\title{
Metzincin Proteases and Their Inhibitors: Foes or Friends in Nervous System Physiology?
}

\author{
Santiago Rivera, ${ }^{1}$ Michel Khrestchatisky, ${ }^{1}$ Leszek Kaczmarek, ${ }^{2}$ Gary A. Rosenberg, ${ }^{3}$ and Diane M. Jaworski ${ }^{4}$ \\ ${ }^{1}$ Neurobiologie des Interactions Cellulaires et Neurophysiopathologie, Unité Mixte de Recherche 6184, Centre National de la Recherche Scientifique, \\ Université de la Méditerranée, 13344 Marseille, France, ${ }^{2}$ The Nencki Institute, 02-093 Warsaw, Poland, ${ }^{3}$ Departments of Neurology, Neurosciences, Cell \\ Biology, and Physiology, University of New Mexico Health Sciences Center, Albuquerque, New Mexico 87131, and ${ }^{4}$ Department of Anatomy and \\ Neurobiology, University of Vermont College of Medicine, Burlington, Vermont 05405
}

Members of the metzincin family of metalloproteinases have long been considered merely degradative enzymes for extracellular matrix molecules. Recently, however, there has been growing appreciation for these proteinases and their endogenous inhibitors, tissue inhibitors of metalloproteinases (TIMPs), as fine modulators of nervous system physiology and pathology. Present all along the phylogenetic tree, in all neural cell types, from the nucleus to the synapse and in the extracellular space, metalloproteinases exhibit a complex spatiotemporal profile of expression in the nervous parenchyma and at the neurovascular interface. The irreversibility of their proteolytic activity on numerous biofactors (e.g., growth factors, cytokines, receptors, DNA repair enzymes, matrix proteins) is ideally suited to sustain structural changes that are involved in physiological or postlesion remodeling of neural networks, learning consolidation or impairment, neurodegenerative and neuroinflammatory processes, or progression of malignant gliomas. The present review provides a state of the art overview of the involvement of the metzincin/TIMP system in these processes and the prospects of new therapeutic strategies based on the control of metalloproteinase activity.

The importance of proteolysis in tissue structure/function is reflected not only in the evolutionary conservation of protease genes in all kingdoms (e.g., from archaea and eubacteria to plants and animals) but also the genomic complexity of this protein class. The "degradome," the repertoire of proteases produced by cells, consists of at least 569 human, 629 rat, and 644 mouse proteases or protease-like proteins and homologs, whereas 156 human protease inhibitor genes have been identified (Puente et al., 2003). The proteases are classified into five major catalytic classes, including metalloproteinases and serine, cysteine, threonine, and aspartic proteinases, with the metalloproteinases representing the largest class (Fig. $1 A$ ). The metzincin family of metalloproteinases is so named for the conserved Met residue at the active site and the use of a zinc ion in the enzymatic reaction. This family comprises matrix metalloproteinases (MMPs), a disintegrin and metalloproteinases (ADAMs), and ADAM proteases with thrombospondin motifs (ADAMTSs). Interest in MMPs be-

\footnotetext{
Received July 5, 2010; revised Sept. 2, 2010; accepted Sept. 20, 2010.

This work was supported by Agence National de la Rercherche Grant ANR-08-MNP-042 and Direction Générale des Armées Grant PEA 070801 (S.R., M.K.), Polish-Norwegian Grant PNRF-96 and 7 Framework Programme of European Union "PLASTICISE" (L.K.), National Institutes of Health (NIH) Grants R01NS052305, R01NS045847, and R21NS066418 (G.A.R.), and a Lake Champlain Cancer Research Organization/Vermont Cancer Center Pilot Project grant, National Institute of Neurological Disorders and Stroke/National Center for Research Resources (NCRR) Grant R01NS045225, and University of Vermont Neuroscience COBRE NIH/NCRR Grant P20 RR016435 (D.M.J.). We are grateful to Grzegorz Wilczynski, Ewelina Knapska, and Piotr Michaluk for critical comments (L.K.) and Holly Stradecki for reference proofreading (D.M.J.).

Correspondence should be addressed to Dr. Diane M. Jaworski, Department of Anatomy and Neurobiology, University of Vermont College of Medicine, 149 Beaumont Avenue, Health Science Research Facility 418, Burlington, VT 05405. E-mail: diane.jaworski@uvm.edu.

DOI:10.1523/JNEUROSCI.3467-10.2010

Copyright $\odot 2010$ the authors $\quad 0270-6474 / 10 / 3015337-21 \$ 15.00 / 0$
}

gan with the identification of an enzyme that contributes to tail resorption during tadpole metamorphosis (collagenase-1, MMP-1) (Gross and Lapiere, 1962) and increased on the discovery that these enzymes not only play a role in normal tissue remodeling but were upregulated in diverse human diseases, including chronic inflammatory disorders and cancer.

\section{MMPs}

MMPs, encoded by 24 human and 23 mouse genes, include secreted and membrane-associated members divided into four main subgroups according to their domain structure, including collagenases, stromelysins, gelatinases, and membrane-type MMPs (MT-MMPs) (Fig. 1B) (Fanjul-Fernández et al., 2010; Ugalde et al., 2010). MMPs contain a signal peptide because most are secreted, likely in vesicles as reported recently in neurons and astrocytes (Sbai et al., 2008, 2010), and function extracellularly. However, intracellular MMP functions have also been reported (Y. S. Kim et al., 2005; Schulz, 2007), as well as active forms of MMP-2, MMP-9, and MMP-13 in the nuclei of neurons and glial cells (Cuadrado et al., 2009; Sbai et al., 2010; Yang et al., 2010). The prodomain contains a cysteine residue that binds zinc in the active site and maintains the MMP in an inactive state. Thus, metzincin proteases are constitutively expressed but remain in a latent state until activated by enzymes that cleave the prodomain or free the cysteine bond. An exception is MT-MMPs, which are activated intracellularly in the Golgi network by the proprotein convertase furin or the serine protease plasmin and, thus, are active during exposure to the extracellular space. Following the catalytic domain is a C-terminal hemopexin (PEX) domain important for determining substrate specificity and interactions 


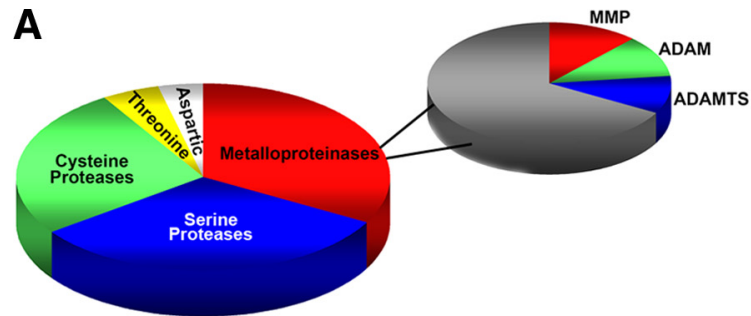

B Archetypal MMPs

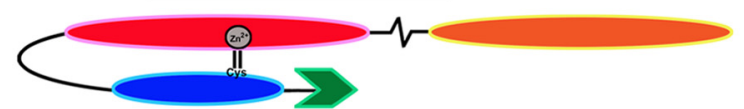

Collagenases: MMP-1, $-8,-13$

Stromelysins: MMP-3, -10

Other MMPs: MMP-12, $-19,-20,-27$

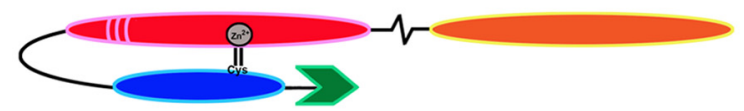

Gelatinases: MMP-2, -9

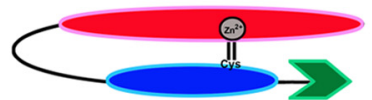

Matrilysins: MMP-7, -26

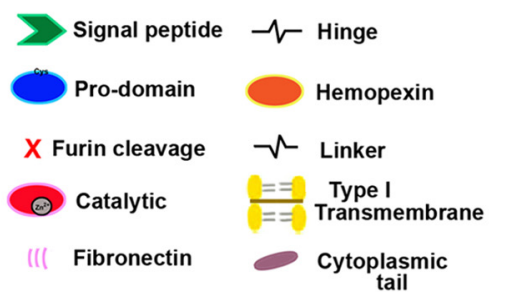

tail

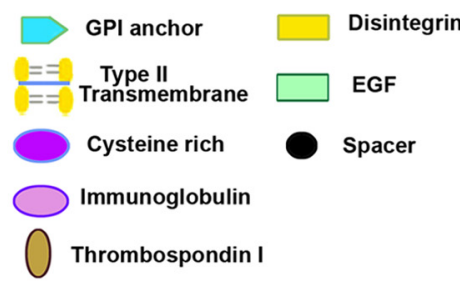

\section{Furin-activated MMPs}

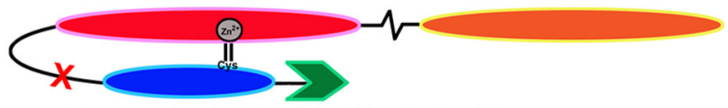

Secreted: MMP-11, $-\mathbf{2 1},-28$
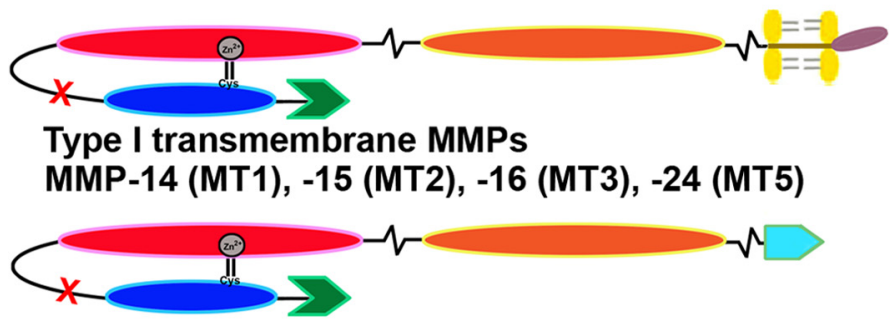

\section{GPI anchored MMPs MMP-17 (MT4), -25 (MT6)}
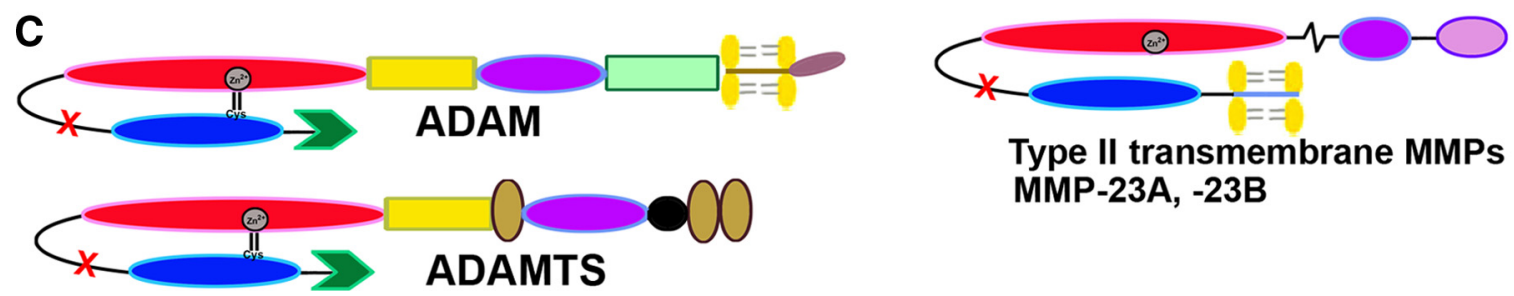

Type II transmembrane MMPs MMP-23A, -23B

Figure 1. Protease classification and structure. $\boldsymbol{A}$, The human degradome, the repertoire of proteases produced by cells, consists of at least 569 proteases and homologs subdivided into five classes: 21 aspartic, 28 threonine, 150 cysteine, and 176 serine proteases and 194 metalloproteases, including MMP, ADAM, and ADAMTS family members. $\boldsymbol{B}$, Structural classification of MMPs based on domain composition, including secreted and membrane-associated MMPs, and MMPs that are activated intracellularly via furin-mediated cleavage. C, Most ADAMs are type I transmembrane protein that possess disintegrin, cysteine-rich, and EGF domains in lieu of the MMP hemopexin domain. ADAMTSs are secreted proteins that contain thrombospondin I motifs in lieu of the EGF domain.

with tissue inhibitors of metalloproteinases (TIMPs), native MMP inhibitors. Matrilysins lack the PEX domain, whereas gelatinases possess three fibronectin II modules within the catalytic domain that improve collagen and gelatin degradation. In keeping with their role in physiological as well as pathological tissue remodeling (Yong, 2005; Page-McCaw et al., 2007; Agrawal et al., 2008; Rosenberg, 2009a), MMP expression is regulated at the level of transcription by a variety of growth factors, cytokines, and chemokines, although posttranscriptional and epigenetic modification may also contribute (Clark et al., 2008). It is now well accepted that MMPs not only degrade extracellular matrix (ECM) proteins of relevance to nervous system physiology [e.g., laminin, the chondroitin sulfate proteoglycan (CSPG) brevican, and the glycoprotein tenascin-R] but also activate growth factors (e.g., proNGF and proBDNF) and their receptors (e.g., trkA, trkC, and p75), cytokines [e.g., pro-tumor necrosis factor- $\alpha$ (proTNF- $\alpha$ ), pro-interleukin-1 $\beta$ (proIL-1 $\beta$ )], and "shed" ECM receptors (e.g., $\mathrm{N}$-cadherin, $\beta$-dystroglycan, and Ephrin-B2) (Schönbeck et al., 1998; Díaz-Rodríguez et al., 1999; McCawley and Matrisian, 2001; Jung et al., 2003; Mateos et al., 2003; Bruno and Cuello, 2006; Ethell and Ethell, 2007; Michaluk et al., 2007; Rodríguez et al., 2010). Because MMP-2, MMP-3, and MMP-9 are the most abundantly expressed MMPs within the brain, antibody reagents are readily available, and MMP-2 and MMP-9 can be easily identified by gelatin zymography, their role in the nervous system has been best characterized.

\section{ADAMs}

ADAMs were first characterized for their involvement in spermegg fusion (Blobel et al., 1992), and, of the 21 human and 37 mouse ADAM genes, seven are primarily expressed in the testis; nonetheless, ADAMs play key roles in neuronal development and function. Several features distinguish ADAMs from MMPs (Fig. 1C) (Edwards et al., 2008). With the exception of the related snake venom metalloproteinases that are secreted, ADAMs are type I transmembrane proteins whose prodomain is generally removed intracellularly. Thus, ADAMs are specialized for juxtamembrane cleavage of other membrane-associated proteins and, hence, are often referred to as "sheddases." The ectodomain shedding either liberates an active extracellular peptide (e.g., TNF- $\alpha$ ) or is essential for subsequent "regulated intramembrane proteolysis" that generates an intracellular domain that translocates to the nucleus and regulates gene expression (e.g., Notch). However, only 13 of the human ADAMs possess proteolytic ac- 
tivity, suggesting that other domains contribute to ADAM biological functions. ADAMs and ADAMTSs possess a disintegrinlike domain that is implicated in interactions with integrins (Bridges and Bowditch, 2005). With the exception of ADAM15, ADAMs lack the classical RGD integrin binding motif but possess a (D/E)ECD motif that contributes to integrin binding specificity and can influence cell adhesion positively (e.g., ADAM-12mediated integrin $\alpha_{6} \beta_{1}$ sperm-egg fusion) (Gupta et al., 2000) or negatively (e.g., snake venom-mediated blockade of platelet aggregation via integrin $\alpha_{\text {IIb }} \beta_{\text {IIIa }}$ ) (Niewiarowski et al., 1994). In contrast, the cysteine-rich domain of ADAMs and ADAMTSs promotes cell adhesion via interaction with syndecans, fibronectin, and other ADAMs (Iba et al., 2000; Gaultier et al., 2002). Most ADAMs, except ADAM-10 and ADAM-17, also have an epidermal growth factor (EGF)-like domain adjacent to the membrane-spanning domain. The cytoplasmic tail of ADAMs is of varying length, with some potentially interacting with Src homology 3 domain-containing signaling molecules (e.g., src, grb), yet a role of ADAMs in signal transduction is not well characterized. At least 17 ADAMs are expressed in the nervous system (for review, see Yang et al., 2006), with ADAM-22, which lacks metalloproteinase activity, and ADAM-23 predominantly present in the nervous system (Sagane et al., 1999). However, ADAM-22 deficient [knock-out (KO)] (Sagane et al., 2005) and ADAM-23 KO (Mitchell et al., 2001) mice exhibit relatively minor phenotypes (e.g., ataxia, gait disturbances, tremor). In contrast, ADAM-10 KO (Hartmann et al., 2002) and ADAM-17 KO (Zhao et al., 2001) mice are embryonic or perinatal lethal. Even conditional knock-out of ADAM-10 in neural progenitor cells results in perinatal lethality (Jorissen et al., 2010). Although ADAM-10 and ADAM-17 get a bad rap for promoting proinflammatory signaling events (e.g., shedding of TNF- $\alpha$, IL-6, and IL-15 receptors), they also exert protective effects in neuronal differentiation, regeneration, and neurodegeneration (e.g., processing of amyloid precursor protein, N-cadherin, Ephrins) (Pruessmeyer and Ludwig, 2009).

\section{ADAMTSs}

Considerable attention has been focused on this family based on their role in thrombotic thrombocytopenic purpura, a form of microangiopathic hemolytic anemia, attributable to autoimmune inhibition of ADAMTS-13-mediated cleavage of von Willebrand factor (Zhou et al., 2010) and arthritis and other connective tissue disorders (e.g., Ehlers-Danlos syndrome attributable to ADAMTS-2 mutation and Weill-Marchesani syndrome attributable to ADAMTS-10 mutation) (Jones and Riley, 2005). Like ADAMs, ADAMTSs are activated intracellularly and secreted in active form. However, unlike ADAMs, ADAMTSs lack a transmembrane domain. Instead, ADAMTSs possess a conserved thrombospondin type 1-like repeat that is believed to function as a binding domain for sulfated glycosaminoglycans present on proteoglycans (Fig. 1C) (Porter et al., 2005). Since the discovery of the first family member (Kuno et al., 1997) and characterization of ADAMTS-1 as the previously identified "aggrecanase" (Sandy et al., 1991), additional ADAMTS members have been reported to cleave aggrecan (e.g., ADAMTS-1, ADAMTS-4, ADAMTS-5, ADAMTS-8, ADAMTS-9, and ADAMTS-15). However, the more global term "hyalectanase" (Gao et al., 2002) may be more relevant because ADAMTSs, particularly ADAMTS-4 and ADAMTS-5, also cleave the hyaluronan binding lectican proteoglycans versican (Sandy et al., 2001) and brevican (Nakamura et al., 2000). Brevican cleavage is of particular relevance to nervous system physiology because of its involvement in synaptic plasticity (Yuan et al., 2002; Mayer et al., 2005) and glioma invasion (Matthews et al., 2000) (discussed in greater detail later in this review). Although substrates have not been identified, evidence suggests that ADAMTSs contribute to neurodegenerative disorders [i.e., ADAMTS-1 expression is increased in Alzheimer's disease (AD) and Down syndrome] (Miguel et al., 2005) and cerebral ischemia (i.e., increased expression of ADAMTS-1, ADAMTS-4, ADAMTS-8, and ADAMTS-9) (Cross et al., 2006a; Tian et al., 2007b; Reid et al., 2009). Both ADAMTS-1 and ADAMTS-8 exert anti-angiogenic effects but display differential temporal upregulation in ischemia, with peak ADAMTS-1 expression at $24 \mathrm{~h}$ after occlusion and peak ADAMTS-8 expression after $3 \mathrm{~d}$ (Tian et al., 2007b); thus, each likely subserves different postischemia effects. Although MMPs play a well accepted role in multiple sclerosis (MS) and experimental autoimmune encephalomyelitis (EAE), the murine MS model (Rosenberg, 2002) (discussed in greater detail below), the contribution of ADAMTSs is less equivocal. ADAMTS-4 expression is decreased in EAE yet increased in MS white matter (Cross et al., 2006b; Haddock et al., 2006). This disparity may be explained, in part, by differential expression (i.e., increased in EAE and decreased in MS) of TIMP-3, the primary ADAMTS inhibitor. Thus, phenotype is driven by the balance between expression of proteases and their endogenous inhibitors.

\section{Metzincin inhibitors}

Three inhibitors negatively regulate metalloproteinase proteolytic activity: $\alpha$-macroglobulin (primary inhibitor in blood and lymphatic tissue), reversion-inducing cysteine-rich protein with Kazal motifs (RECK), and TIMPs. Thus far, RECK has been reported to inhibit a rather small repertoire of proteases (e.g., MMP-2, MMP-9, and MT1-MMP) and primarily within the context of tumorigenesis (Takahashi et al., 1998; Oh et al., 2001; Liu et al., 2003). Nonetheless, RECK appears to modulate Notchmediated cortical neurogenesis by regulating ADAM-10 activity (Muraguchi et al., 2007). Hence, TIMPs represent the principal endogenous metalloproteinase inhibitors (Brew and Nagase, 2010). Four highly conserved TIMP genes are present in humans and mice. Among the TIMPs, TIMP-1 has the most restricted inhibitory range because it shows low affinity for MT-MMPs and exhibits adult CNS expression primarily restricted to regions of persistent neuronal plasticity, such as the hippocampus, olfactory bulb, and cerebellum (Rivera et al., 1997; Fager and Jaworski, 2000). The relative restricted tissue distribution of TIMP-4 (e.g., heart, kidney, pancreas, colon, testes, brain, and adipose tissue) suggests that it plays a role in tissue-specific physiological functions (Greene et al., 1996), but little else is known about this molecule (Melendez-Zajgla et al., 2008). TIMP-3 has the broadest inhibition spectrum, inhibiting several ADAM and ADAMTS proteases, and is the only TIMP bound to the ECM (Leco et al., 1994). TIMP-2 is the most abundantly expressed TIMP in the brain (Fager and Jaworski, 2000) and not only inhibits MMP-2 but, paradoxically, also contributes to proMMP-2 activation (Butler et al., 1998). Indeed, TIMP-2 forms a trimolecular complex with MT1-MMP and proMMP-2 and is required for MT1MMP-mediated activation of proMMP-2. Hence, proMMP-2 activation is impaired in its absence (i.e., TIMP-2 KO mice) (Caterina et al., 2000; Wang et al., 2000). Similar proMMP interactions occur (e.g., TIMP-1 and proMMP-9), but this interaction is not required for proMMP activation. Although other MMPs can activate proMMP-2 independent of TIMP-2 (e.g., MT2-MMP) (Morrison et al., 2001), MT1-MMP is principally responsible for proMMP-2 activation. In addition to their dual roles in MMP 
inhibition and MMP activation, TIMPs exert diverse biological functions (e.g., cell cycle, anti-angiogenesis, apoptosis) independent of MMP interaction (Crocker et al., 2004; Chirco et al., 2006; Stetler-Stevenson, 2008b). Inhibitors specifically targeting these MMP-independent functions may be exploited therapeutically without altering tissue integrity.

\section{Confounding factors in metzincin biology}

The development of efficacious analytical tools has supported progress in the metzincin field, but investigating the expression and role of these proteinases still encounters limitations. Perhaps one of the most important is the paucity of selective synthetic metzincin inhibitors, principally because of the high level of structural conservation in their catalytic sites. Some inhibitors have been reported to selectively inhibit MMP-2, MMP-9, MMP11, MMP-12, MMP-13, and MMP-14, ADAM-17, and ADAMTS-4 and ADAMTS-5, whereas some compounds that broadly inhibit MMPs spare ADAMs (at least ADAM-17). Exhaustive information on current progress in the ability to design specific metzincin inhibitors (including synthetic, antibody-based or endogenous inhibitors) can be found in specialized reviews (Fisher and Mobashery, 2006; Yiotakis and Dive, 2008; Brew and Nagase, 2010; Sela-Paswell et al., 2010). Additional difficulties stem from the use of commercially available antibodies. Most commercial antibodies were initially developed to human antigens for use in clinical studies, but many of these reagents displayed limited cross-reactivity with other species. Thankfully, this limitation is waning as companies develop antibodies to murine antigens. Nonetheless, antibodies may not display sufficient sensitivity to detect the low level of metzincins present in some cell types or subcellular compartments and multiple antibodies often need to be tested. Immunocytochemistry also fails to detect the subcellular localization of the latent versus active forms of the enzymes. Although this may be accomplished by molecular mass on Western blots, it does not provide information about their inhibitorbound or free state in the cell. The highly sensitive technique of gel zymography detects picogram levels of the zymogen and active forms of gelatinases MMP-2 and MMP-9 on the basis of their ability to cleave gelatin in SDS-PAGE. Nevertheless, gel zymography is hardly useful for other MMPs and reflects the steady-state levels of MMPs rather than their activity in the tissue. In situ zymography partially alleviates this problem because the fluorescence resulting from the cleavage of FITCquenched gelatin added to fresh tissue slices or cells represents the net in situ balance between active gelatinases and their endogenous inhibitors. However, this technique reveals the net activity of all gelatinases, not just MMP-2 and MMP-9. Thus, the use of inhibitors (e.g., serine proteinases) is recommended to ascertain the nature of the proteolytic activity. These few examples illustrate the limitations of widely used tools and bring about the opportunity of combining them with molecular tools (small interfering RNA, antisense oligonucleotides, genetically engineered molecules, cells, and mice) to better assess the biology of a specific proteinase.

This brief review of metzincin structure and function has only given the reader a small glimpse into the complexity of this fascinating protein family. The four reviews that follow highlight the contributions of these proteases and their inhibitors in nervous physiology and pathology, with special emphasis on the concept that not all proteolysis has negative consequences.

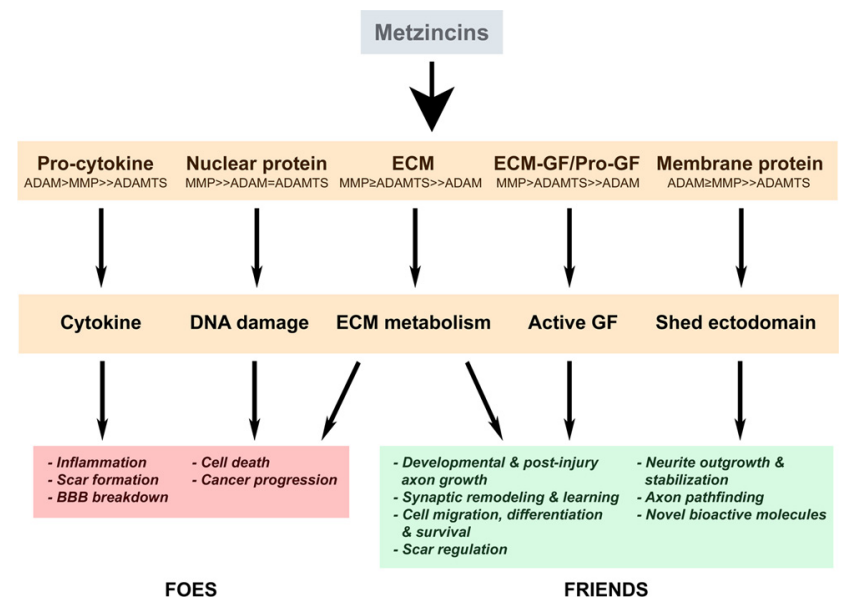

Figure 2. Physiopathological consequences of metzincin-substrate interactions. Nonexhaustive representation of interactions between metzincins and putative substrates in the nervous system, leading eventually to detrimental or beneficial effects in different physiological and pathological settings. The hierarchy between proteinase subtypes is established on the basis of current knowledge on metzincin actions and substrate preferences in the nervous system. The substrates include cytokines, soluble or ECM-bound growth factors (GF), and nuclear or membrane proteins. Metzincin-mediated proteolysis may lead to the following: (1) conversion of latent forms of proinflammatory cytokines (e.g., TNF $\alpha$, IL-1 $\beta$, etc.) or growth factors (e.g., BDNF, NGF) into their biologically active forms; (2) cleavage of nuclear (e.g., DNA repair enzymes) or ECM proteins (e.g., CSPGs, laminin, tenascin) causing irreversible changes in their structure and function; (3) cleavage of membrane proteins leading to their activation or inactivation or to the release of soluble ectodomains with, in most cases, yet unknown biological activity.

\section{Metzincins and TIMPs at the crossroads of developmental and postinjury plasticity}

Although metzincins and TIMPs have been mostly studied in the context of nervous system disease and injury, the past decade has witnessed a growing interest of neuroscientists for their role in developmental plasticity and repair. The molecular and cellular events that support postlesion repair of the mature CNS recapitulate some of the processes set in motion during development. Strong evidence now indicates that the metzincin/TIMP system plays critical roles in these phenomena (Fig. 2, Table 1).

Metzincins and TIMPs in developmental processes

The increased interest in metzincin proteinases notwithstanding, the expression of all metzincins and TIMPs has not been evaluated in all cell types or regions of the nervous system. Relatively high mRNA and protein levels of MMP-2, MMP-11, MMP-13, MMP-14, MMP-15, and MMP-24 and TIMP-1 and TIMP-3 are found in the perinatal rodent CNS but generally decline with age (Rivera et al., 1997; Vaillant et al., 1999; Fager and Jaworski, 2000; Jaworski, 2000; Ayoub et al., 2005; Ulrich et al., 2005; Ranasinghe et al., 2009). In contrast, TIMP-2 and TIMP-4 increase with age (Fager and Jaworski, 2000; Ulrich et al., 2005), and MMP-12 levels peak at 4-5 postnatal weeks, coincident with the peak of myelination (Ulrich et al., 2005). Less is known about the developmental regulation of other metzincin family members. ADAMTS-9 expression is restricted to the floor plate of the diencephalon and cerebral cortical ventricular zone (Jungers et al., 2005), yet its function in corticogenesis has not been investigated. These data suggest that each MMP and TIMP likely subserves distinct developmental functions.

The MMP/TIMP system has been shown to influence neural cell differentiation and survival. TIMP-2 acts in synergy with NGF to induce cell cycle arrest of neuronal precursors and promote neuronal differentiation (Pérez-Martínez and Jaworski, 
Table 1. Metzincin functions in the nervous system

\begin{tabular}{|c|c|c|}
\hline Metzincin & Physiological function & Postinjury function \\
\hline \multirow[t]{3}{*}{ MMP-2 } & Neurite outgrowth ${ }^{c}$ & Axonal regeneration and tissue \\
\hline & Astrocyte motility ${ }^{b}$ & repair \\
\hline & PNS myelination ${ }^{b}$ & \\
\hline \multirow[t]{2}{*}{ MMP-3 } & Neurite outgrowth ${ }^{c}$ & \\
\hline & Neural cell survival' & \\
\hline MMP-7 & Neurotrophin convertase $^{a}$ & \\
\hline \multirow[t]{4}{*}{ MMP-9 } & Neurite outgrowth & Excitotoxic neuronal death ${ }^{c}$ \\
\hline & $\begin{array}{l}\text { Neural cell precursor migration } \\
\text { and survival }^{a}\end{array}$ & Scar formation ${ }^{c}$ \\
\hline & $\begin{array}{l}\text { Oligodendrocyte maturation } \\
\text { and myelination }\end{array}$ & Remyelination $^{a}$ \\
\hline & NGF degradation ${ }^{a}$ & Neural cell precursor mobilization ${ }^{c}$ \\
\hline MMP-12 & $\begin{array}{l}\text { Oligodendrocyte maturation } \\
\text { and myelination }{ }^{c}\end{array}$ & Secondary damage in $\mathrm{SCl}^{c}$ \\
\hline MMP-24 & & Spinal cord axonal sprouting ${ }^{c}$ \\
\hline MT-MMPs & Neuroblast migration ${ }^{b}$ & \\
\hline \multirow[t]{2}{*}{ ADAM-10 } & $\begin{array}{l}\text { Axonal extension, }{ }^{a} \text { guidance }_{,}{ }^{a} \\
\text { and stabilization }{ }^{c}\end{array}$ & \\
\hline & $\begin{array}{l}\text { Neuronal migration and differ- } \\
\quad \text { entiation }^{a}\end{array}$ & \\
\hline ADAM-17 & & $\begin{array}{l}\text { Neurite outgrowth in the presence } \\
\text { of myelin ligands }{ }^{c}\end{array}$ \\
\hline ADAMTS-4 & Neurite outgrowth ${ }^{a}$ & \\
\hline ADAMTS-5 & Neurite outgrowth ${ }^{a}$ & \\
\hline
\end{tabular}

Findings have been obtained mostly with ${ }^{a}$ molecular, ${ }^{b}$ pharmacological, or both molecular and pharmacological approaches. Pharmacological approaches essentially use metzincin inhibitors, whereas molecular approaches include the use of recombinant metzincins or gain-loss-of-function engineered molecules. SCI, Spinal cord injury; NGF, nerve growth factor; PNS, peripheral nervous system.

2005), whereas MMP-9 and MMP-12 regulate oligodendrocyte maturation and myelination possibly through the modulation of insulin-like growth factor bioavailability (Larsen et al., 2006). A role for MMP-2 in peripheral nervous system myelination has also been reported recently in a coculture model of Schwann cells and dorsal root ganglia (DRG) neurons (Lehmann et al., 2009). Moreover, cell culture studies have shown that MMP-3 can promote neural cell survival by suppressing Fas ligand-mediated programmed cell death signaling (Wetzel et al., 2003). In vivo, postnatal programmed cell death of cerebellar granule cell precursors is reduced in MMP-9 KO mice (Vaillant et al., 2003). These data underscore the importance of positive roles for MMPs in neuronal survival.

Cell migration is another pivotal developmental function that involves metzincin activities. Migration of cerebellar granule cell precursors correlates with changes in MMP-9 expression, and external granular layer migration is delayed in MMP-9 KO mice or after blockade of MMP-9 activity with neutralizing antibodies in cerebellar explants (Vaillant et al., 2003). Another gelatinase, MMP-2, regulates the motility of cultured nonstimulated astrocytes possibly via an interaction with $\beta 1$ integrins and the actin cytoskeleton (Ogier et al., 2006). The migration of individual neuroblasts along the rostral migratory stream (RMS) from the subventricular zone (SVZ) to the olfactory bulb or those migrating radially within the olfactory bulb is perturbed after birth by furin inhibitors thought to inhibit the activation of MT-MMPs (Bovetti et al., 2007). The expression of TIMP-3, a physiological MT-MMP inhibitor, in the SVZ and RMS (Jaworski and Fager, 2000) may negatively regulate neuroblast migration. Besides MMPs, a central role for ADAM-10 in brain development has been demonstrated recently. Conditional KO of ADAM-10 specifically in neural progenitor cells induces aberrant neuronal migration and a disorganized laminar neocortical architecture attributable to precocious neuronal differentiation and consequent early depletion of progenitor cells (Jorissen et al., 2010).

Perhaps the most critical role of metzincins in developmental plasticity is regulation of neurite outgrowth. Metalloproteinase activity is permissive for axonal extension via cleavage of inhibitory ECM proteins (e.g., CSPGs). ADAMTS-4 and ADAMTS-5 promote neurite outgrowth (Hamel et al., 2008) via brevican cleavage (Hamel et al., 2005). ADAMTS-4 also enhances neurite outgrowth via a mechanism that does not require proteolysis but is dependent on activation of mitogen-activated protein (MAP) extracellular signal-regulated kinase 1/2 (ERK1/2) kinase (Hamel et al., 2008). Thus, like TIMPs, metzincin proteases also exert effects that are independent of proteolytic activity. MMPs also mobilize ECM-sequestered trophic factors, such as EGF (Suzuki et al., 1997). In addition, MMP-7 can proteolytically convert the pro-forms of BDNF and NGF into the biological active forms (Lee et al., 2001), and MMP-9 degrades active NGF (Bruno and Cuello, 2006). In turn, NGF and BDNF can stimulate the expression and activity of MMP-2, MMP-9, and MMP-14 (Machida et al., 1991; Muir, 1994; Cazzin et al., 2010). This proteolysis can either activate or inhibit signaling pathways. Broad-spectrum metalloproteinase inhibitors prevent shedding of deleted in colorectal cancer, a receptor for the guidance factor netrin-1, which potentiates ligand-receptor interactions and consequent netrinmediated axon outgrowth of cultured rat embryonic DRG neurons (Galko and Tessier-Lavigne, 2000). The same inhibitors provoke pathfinding errors in retinal ganglion cell axons along the optic chiasm during Xenopus development (Webber et al., 2002). The Kuzbanian protein (the Drosophila homolog of vertebrate ADAM-10) is required for normal axon extension (Fambrough et al., 1996) and controls midline crossing of axons in the CNS via proteolytic activation of the Slit/Robo receptor complex in commissural axons (Schimmelpfeng et al., 2001). ADAM-10 also controls axon stabilization and progression through the proteolytic cleavage of chemorepellent ephrins (Hattori et al., 2000) via a mechanism that requires the formation of an ADAM-10/ Eph receptor complex that precedes Eph cleavage (Janes et al., 2005). Although most studies principally suggest the involvement of ADAMs in axon guidance, recent reports posit that MMP-3 and MMP-2 contribute to axon guidance and dendrite extension of embryonic cultured cortical neurons in response to Sema3C and Sema3A signaling, respectively (Gonthier et al., 2007, 2009). In the same culture model, a truncated form of TIMP-1 lacking the C-terminal domain inhibits neurite outgrowth via its MMP-inhibitory N-terminal domain, most likely by targeting MMP-2 (Ould-yahoui et al., 2009). Altogether, these data reinforce the idea that metzincins and TIMPs may work in concert to regulate neurite extension/ pathfinding during development.

\section{Metzincins and TIMPs in postinjury plasticity}

Metzincins also play a role in postinjury plasticity, particularly via the regulation of the glial scar. The glial scar effectively confines the lesion but also constitutes a major obstacle for axon regeneration, partially because of the accumulation of inhibitory molecules (e.g., CSPGs, myelin ligands). Pioneer studies demonstrated that MMP-2-mediated CSPG proteolytic processing promotes axonal outgrowth of DRG neurons and unveils the growth-promoting effect of associated laminin (Zuo et al., 1998). Analogous effects on neurite outgrowth were reported for MMP-24-mediated CSPG cleavage in cultured DRG neurons (Hayashita-Kinoh et al., 2001). Furthermore, the inhibitory effect of CNS myelin on DRG neurite outgrowth is removed by 
the ADAM-17-mediated cleavage of the neurotrophin receptor p75, acting upstream of Rho-A inactivation (Ahmed et al., 2006).

The involvement of TIMPs in glial scar formation finds support in the high levels of astrocytic TIMP-1 and TIMP-2 observed in nonregenerating areas after optic nerve injury compared with lower levels found in regenerating areas (Ahmed et al., 2005). Also, the finding that TIMP-1 is mitogenic for astrocytes, unlike broad-spectrum MMP inhibitors (Ogier et al., 2005, 2006), suggests a role for TIMP-1 in postinjury gliosis through a mechanism independent of MMP inhibition. Accordingly, knocking out TIMP-1 targets such as MMP-2 or MMP-9 has no effect on astrocyte mitogenesis in culture (Hsu et al., 2008). This is similar to the MMP-independent actions of TIMP-2 on neuronal differentiation via the interaction of TIMP- 2 and integrin $\alpha 3 \beta 1$ (PérezMartínez and Jaworski, 2005). These studies illustrate a yet relatively unexplored domain of the signal transduction pathway(s) triggered by TIMPs or MMPs independent of proteolysis modulation.

After spinal cord injury, in situ zymography reveals increased gelatinase activity along regenerating axons in the scar tissue (Duchossoy et al., 2001). Accordingly, MMP-2 KO mice exhibit reduced spontaneous axon regeneration and functional recovery with a concomitant increase in CSPG levels after moderate spinal cord injury (Hsu et al., 2006). The same authors suggest that MMP-9 contributes to the early deleterious effects of spinal cord injury (Goussev et al., 2003) and to astrocyte motility during glial scar formation (Hsu et al., 2008). However, MMP-9 action may follow some region and/or lesion specificity because the formation of the glial scar is not altered in the cortex or striatum of MMP-9 KO mice after focal ischemia (Copin and Gasche, 2007). Other authors have shown in $\mathrm{KO}$ mice with spinal cord injury that MMP-9 facilitates remyelination via processing of the inhibitory proteoglycan NG2 (Larsen et al., 2003), whereas MMP-12 mediates the permeability of the blood-spinal cord barrier and activation of mononuclear phagocytes (Wells et al., 2003). MMP-24 KO mice do not display dorsal horn A $\beta$ fiber sprouting normally observed after sciatic nerve injury, suggesting a possible explanation for the absence of mechanical allodynia in the mutant mice (Komori et al., 2004). These data stress the beneficial and detrimental effects of MMPs and point to MMP-9 as probably the best example of this functional duality.

Excitotoxic neuronal hyperactivity is also a strong inducer of MMP and TIMP expression. Kainate (KA)-induced seizures in rats sequentially upregulate TIMP-1 in hippocampal dentate granule cells and reactive astrocytes (Rivera et al., 1997). In the same animal model, transient upregulation of MMP-9 expression and gelatinase activity in dendritic areas of the dentate gyrus (DG) have been related to postseizure tissue remodeling of this area (Szklarczyk et al., 2002), whereas MMP-9 appears to be deleterious for pyramidal hippocampal cells (Jourquin et al., 2003). Transient early postseizure upregulation of MMP-9 is followed by steady augmentation of MMP-2 over 4 weeks, coincident with mossy fiber sprouting (Jourquin et al., 2005). The same study showed that TIMP-1 KO mice undergoing seizures do not exhibit MMP upregulation or axonal sprouting, suggesting that coregulation of TIMP-1 and MMPs is necessary to support postseizure sprouting. The implication of MMPs in axo-dendritic remodeling finds additional support in invertebrate models in which Drosophila MMPs are required to degrade dendrites before largescale reorganization of sensory neuron dendritic arbors during metamorphosis (Kuo et al., 2005). Thus, several MMPs may cooperate in sequential events in which an initial disruption of the dendritic arbor paves the way for eventual sprouting of hippocampal mossy fibers.

The effect of MMPs in neuronal regeneration has recently lead researchers to question whether the regenerative properties of exogenously grafted cells could rely on MMP activity-based mechanisms. Several MMPs, including MMP-2 and MMP-9, and the four TIMPs are expressed in neural precursors in vivo and in vitro (Frölichsthal-Schoeller et al., 1999; Ben-Hur et al., 2006; Lee et al., 2006). MMP-9 is abundantly expressed in neuroblasts migrating from the SVZ into the injured striatum in response to focal ischemia in mice, and MMP inhibitors interfere with this migration (Lee et al., 2006). Transplantation of CNS progenitor cells into explants of degenerating retina promotes neurite extension in response to increased MMP-2 secretion by host glial cells and the concomitant proteolytic processing of the neurite outgrowth inhibitors CD44 and neurocan (Zhang et al., 2007). Likewise, MMP-2 produced by rat olfactory ensheathing cells cocultured with adult retinal cells promotes axon growth coincident with CSPG cleavage (Pastrana et al., 2006). Altogether, these findings highlight positive roles for metzincins in cell-mediated injury repair through the mobilization of endogenous neural cell precursors and the remodeling of the lesion environment by grafted cells.

In summary, the data reviewed herein brings about compelling evidence about the functional relevance of metzincins and TIMPs at the crossroads of physiological and postinjury neural plasticity. Much work remains to be done for a comprehensive vision of the biology of these molecules and the way we may control them in the prospects of designing neuroregenerative therapies.

\section{Metzincins and TIMPs contribute to learning and memory as well as human neuropsychiatric disorders}

In addition to developmental plasticity (discussed above), there are multiple physiological and pathological phenomena relying on plasticity within the adult brain, including learning and memory, epileptogenesis, and drug addiction, to name just a few. Several experimental paradigms mimicking some aspects of plasticity have also been identified, with long-term potentiation (LTP) and long-term depression (LTD) being the most prominent. Myriad molecules have been proposed to play a role in brain plasticity. Most studies focus on external information conveyed to neurons predominantly by means of neurotransmitters, neurotrophins, cytokines, and steroids. However, much less is known about a major extracellular molecular brain structure surrounding neuronal synapses, i.e., ECM and cell adhesion molecules. Because plasticity is associated with postsynaptic structural alterations, proteolytic ECM modifications likely contribute to plasticity.

\section{MMPs/TIMPs in long-term potentiation and learning}

The first indication that the MMP/TIMP system plays a role in neuronal plasticity was provided by Nedivi et al. (1993) who demonstrated TIMP-1 mRNA upregulation within the DG on both KA-induced seizures and stimuli leading to LTP. KA treatment provokes a massive neuronal excitation that results in neuronal loss in the CA1/CA3 hippocampal subfields but spares the DG, which undergoes plastic reorganization instead (ZagulskaSzymczak et al., 2001). Szklarczyk et al. (2002) suggested that MMP-9 might also be relevant for neuronal plasticity because they found that MMP-9 mRNA, protein, and enzymatic activity were all selectively increased in the DG after KA-evoked seizures. Interestingly, MMP-9 and TIMP-1 are subject to gene regulation 
by AP-1, a transcription factor composed of Fos and Jun proteins that has been closely associated with neuronal plasticity (Jaworski et al., 1999; Kaczmarek et al., 2002; Rylski et al., 2009).

Several reports support a role for MMPs in physiological LTP at diverse brain regions. The pivotal role for MMP-9 in LTP was first established by Nagy et al. (2006) who revealed that MMP-9 protein levels and proteolytic activity were rapidly increased by stimuli that induce late-phase LTP. Furthermore, using MMP-9 KO mice, as well as broad-spectrum MMP inhibitors, the authors reported deficient late-phase LTP in hippocampal slices at the CA3 to CA1 pathway. A role for MMPs, using broad-spectrum inhibitors, has also been reported for DG-CA3 (mossy fiber) LTP in the hippocampus (Wójtowicz and Mozrzymas, 2010). Inhibition of MMP activity with MMP-3 and MMP-9 antisense oligonucleotides, chemical MMP inhibitors, or neutralizing antibodies also altered hippocampal LTP (Meighan et al., 2006; Bozdagi et al., 2007; Meighan et al., 2007; Wang et al., 2008; Conant et al., 2010). Notably, hippocampal MMP-3 expression and activity increased during trauma-induced synaptogenesis, and MMP inhibition altered functional and structural correlates of deafferentiation-induced sprouting in the DG (Reeves et al., 2003; H. J. Kim et al., 2005; Falo et al., 2006). In addition to hippocampal LTP, blocking MMP-9 by either a specific chemical inhibitor or TIMP-1 overexpression impaired late-phase LTP, but not its induction, in the subiculum to prefrontal cortex pathway (Okulski et al., 2007). Disruption of MMP-9 activity also abolished late-phase LTP in the basolateral to central nucleus of the amygdala, but LTP in the cortical pathway leading to the lateral amygdala remained essentially intact (M. Balcerzyk, V. Lioudyno, A. Kiryk, T. Górkiewicz, P. Michaluk, M. Gawlak, G. M. Wilczyński, L. Kaczmarek, E. Knapska, unpublished observations). Together, these data indicate that MMPs are involved in various aspects of LTP, with MMP-9 needed for late-phase LTP and MMP-3 for LTP induction. In this context, it is noteworthy that MMP-3 acts upstream of MMP-9 (i.e., MMP-3 regulates MMP-9 activation) (Ogata et al., 1992).

Given the role of MMPs in hippocampal LTP, it comes as no surprise that MMP inhibition has also been linked to memory deficits in behavioral learning paradigms (Nagy et al., 2006, 2007; Wright et al., 2007, 2009; Brown et al., 2009; Wiediger and Wright, 2009). Specifically, MMP-3 was activated by passive (inhibitory) avoidance and habituation of the head-shake response (Wright et al., 2006; Olson et al., 2008), and MMP-9 activity was increased after Morris water maze, head-shake response, and passive avoidance (Meighan et al., 2006; Wright et al., 2006; Nagy et al., 2007). Furthermore, MMP-9 KO mice displayed poor memory in contextual fear conditioning and appetitive learning in the IntelliCage system (Nagy et al., 2006; Brown et al., 2009; M. Balcerzyk, V. Lioudyno, A. Kiryk, T. Górkiewicz, P. Michaluk, M. Gawlak, G. M. Wilczyński, L. Kaczmarek, E. Knapska, unpublished observations). However, no effect of MMP-9 KO was demonstrated for discrete cue conditioning or aversive learning in the IntelliCage system (Knapska et al., 2006; Nagy et al., 2006; M. Balcerzyk, V. Lioudyno, A. Kiryk, T. Górkiewicz, P. Michaluk, M. Gawlak, G. M. Wilczyński, L. Kaczmarek, E. Knapska, unpublished observations). Because the lateral amygdala has been specifically implicated in the two latter paradigms, these findings are in accord with the LTP data discussed above. These studies clearly support a role for MMPs in learning but also demonstrate specificity driven by anatomic location and/or molecular substrates.

The subcellular localization of MMPs makes them ideally suited for the regulation of neuronal plasticity. For example, MMP-9 mRNA, protein, and enzymatic activity are present at the
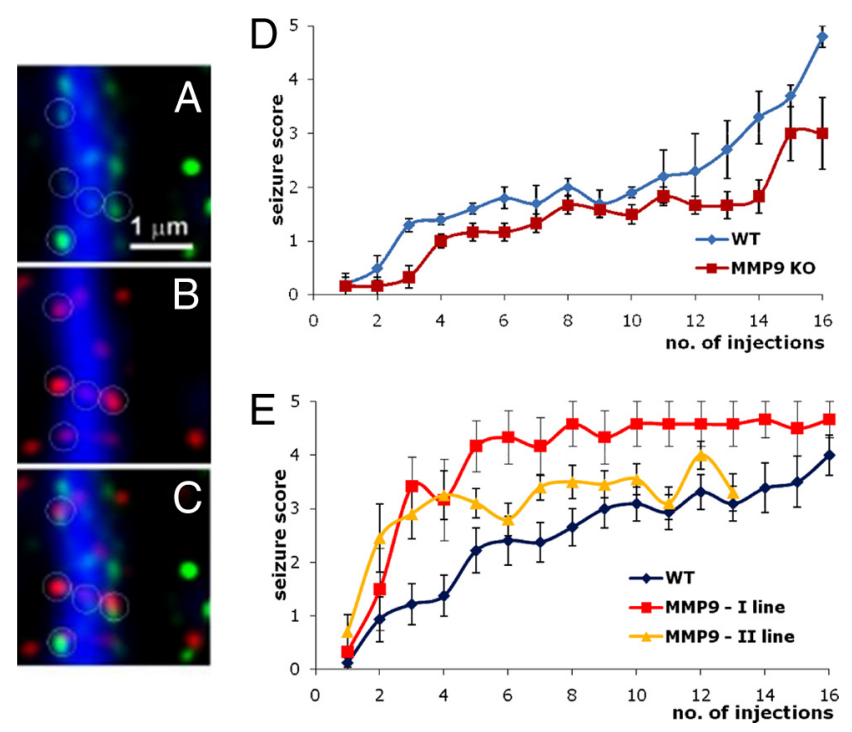

Figure 3. MMP activity is expressed at synapses, and MMP-9 plays a role in aberrant plasticity subserving epileptogenesis. $A$, MMP (gelatinolytic) activity revealed by in situ zymography (green) along a dendrite (blue, MAP-2 antibody staining). $\boldsymbol{B}$, Dendritic spines (red, antibody staining against drebrin) along a dendrite. $C$, Colocalization of gelatinolytic activity and spine marker. D, MMP-9 KO mice and their wild-type siblings were treated to chemical kindling (an epileptogenic process) by repeated intraperitoneal injections of pentylenetetrazole ( $35 \mathrm{mg} / \mathrm{kg}$, every 2-3 d). Seizure score reflects increasing severity of convulsions from 1 to 5 . Note that MMP-9 KO are less susceptible to epileptogenesis. $\boldsymbol{E}$, Pentylenetetrazole kindling in wild-type (WT) and transgenic (TG) rats overexpressing an autoactivating form of MMP-9 in neurons; two lines of transgenic rats were generated and subjected to kindling. Note that the transgenic rats are more prone to the epileptogenesis (for details on $\boldsymbol{A}-\boldsymbol{C}$, see Gawlak et al., 2009; for details on $\boldsymbol{E}$ and $\boldsymbol{D}$, see Wilczynski et al., 2008).

postsynaptic domains of excitatory synapses (i.e., at dendritic spines) (Konopacki et al., 2007; Sbai et al., 2008; Wilczynski et al., 2008; Gawlak et al., 2009) (Fig. 3A-C). LTP-producing stimuli evoke local MMP-9 release, which affects spine morphology (Wang et al., 2008; Bilousova et al., 2009). Specifically, MMP-9 drives dendritic spine enlargement and LTP coordinately, thus playing an instructive role in establishing persistent modifications in both synapse structure and function (Wang et al., 2008).

The following molecular scenario may underlie MMP-9 involvement in synaptic plasticity. When glutamate binds to its receptor (e.g., NMDA receptor), a signaling cascade is set in motion that results in local MMP-9 release. The exact nature of the molecular events taking part in MMP-mediated plasticity remains elusive; however, $\beta$-dystroglycan, ICAM-5, and integrins, especially $\beta 1$ integrins, appear to be involved (Nagy et al., 2006; Michaluk and Kaczmarek, 2007; Tian et al., 2007a; Michaluk et al., 2009; Conant et al., 2010). Because MMP-9 is proteolytically activated outside the cell and cannot be recuperated, translation, release, and/or activity trigger signals that initiate an MMP-9 replenishment process. This involves production of the c-Fos/ AP-1 transcription factor, MMP-9 gene expression, translocation of MMP-9 mRNA toward dendrites and synapses, and local dendritic translation. Given its role in neuronal cell loss (Michaluk and Kaczmarek, 2007), excessive MMP-9 could be harmful; thus, its gene expression is prevented by transcriptional silencers, including AP-1 of a different composition (i.e., JunB) (Rylski et al., 2009). MMP activity is also regulated by interaction with TIMPs.

TIMPs have also been shown to affect learning and memory. In an olfactory maze, TIMP-1 KO mice were significantly impaired in making correct odor reward, whereas TIMP-1 overexpressing mice performed better than their wild-type controls 
(Jourquin et al., 2005; Chaillan et al., 2006). In TIMP-2 KO mice, a deficiency in fear-potentiated startle response has been revealed (Jaworski et al., 2005). Finally, TIMP-3 KO mice exhibited deterioration in cognitive function in the water maze and decreased habituation in the open-field test (Baba et al., 2009).

\section{ADAMTS and ADAM family members in neuronal plasticity} Although less well characterized, ADAMTS and ADAM family members also contribute to synaptic plasticity. Brevican, the most abundantly expressed member of the lectican family of CSPGs in the adult brain, stabilizes synapses and inhibits neuronal plasticity. ADAMTS-mediated brevican cleavage is enhanced in response to KA treatment (Yuan et al., 2002) and entorhinal cortex lesion (Mayer et al., 2005) and may modulate synaptic reorganization. Cleavage of the neuronal pentraxin receptor by ADAM-17/tumor necrosis factor- $\alpha$ converting enzyme (TACE) is required for metabotropic glutamate receptor subunit $1 / 5$ (mGluR1/5)-dependent internalization of AMPA receptor and mGluR1/5-dependent LTD in both the hippocampus and cerebellum (Cho et al., 2008). Although a role for ADAM-21 in neurogenesis and plasticity has been proposed (Yang et al., 2005), potential ADAM-21 substrates have yet to be identified (Yang et al., 2006). ADAM-10, an $\alpha$-secretase, cleaves amyloid precursor protein within the $\mathrm{A} \beta$ sequence and thus prevents amyloid peptide formation. ADAM-10 overexpressing mice display enhanced cortical plasticity (Bell et al., 2008) and rescued LTP deficiency in the AD model mice (Postina et al., 2004) and positively influences learning and memory (Schmitt et al., 2006). Thus, ADAM-10 may serve as a therapeutic target for $\mathrm{AD}$ (Endres and Fahrenholz, 2010).

\section{MMPs in epilepsy}

Various conditions believed to be subserved by abnormal synaptic plasticity have been reported to involve MMP-9. For instance, epileptogenesis produced by pentylenetetrazole kindling was disturbed in MMP-9 KO mice and, conversely, promoted in MMP-9 overexpressing rats (Wilczynski et al., 2008) (Fig. 3 D,E). A role of MMP-9 in the development of epilepsy has also been supported by studies in pilocarpine- and 4-aminopyridine-treated animal models (Kim et al., 2009; Takács et al., 2010).

\section{MMPs in addiction}

A functional role for MMPs and TIMPs has also been revealed in drug addiction. Intracerebral injection of a broad-spectrum MMP inhibitor suppressed acquisition of cocaine-dependent place preference and attenuated cocaine-primed reinstatement after extinction of the response (Brown et al., 2007). Furthermore, increased MMP-9 was observed in the medial prefrontal cortex after cocaine reinstatement of the conditioned place preference (Brown et al., 2007). Moreover, increased MMP-2 and MMP-9 activity in both neurons and glia were observed in the frontal cortex and nucleus accumbens after methamphetamine addictive treatment and diminished behavioral response to treatment was noted in both MMP-2 and MMP-9 KO mice (Mizoguchi et al., 2007b). Furthermore, both strains of mutant mice exhibited resistance to the inhibitory effect of treatment on dopamine transport activity (Mizoguchi et al., 2007b). Similar effects were observed after application of an MMP-2/9 inhibitor (Mizoguchi et al., 2007a). In addition, repeated methamphetamine treatment increased TIMP-2 expression, and antisense TIMP-2 oligonucleotide enhanced the behavioral effects as well as methamphetamine-induced dopamine release in the nucleus accumbens (Mizoguchi et al., 2007a). Moreover, repeated drug treatment reduced dopamine $\mathrm{D}_{2}$ receptor-dependent signaling in wild-type mice but not MMP-9 or MMP-2 KO mice (Mizoguchi et al., 2007a). Recently, W. T. Liu et al. (2010) have reported that MMP-9 in the spinal cord contributes to morphine withdrawal-like behavioral signs in mice. It has also been reported that ethanol-induced impairment of water maze learning correlated with reduced hippocampal and prefrontal cortex MMP-9 activity (Wright et al., 2003).

The aforementioned results linking the MMP/TIMP system to drug addiction obtained with animal models are also reinforced in humans. Serum MMP-9 levels are greater in alcoholics (Sillanaukee et al., 2002), and alcoholics exhibit a twofold increased frequency of an MMP-9 promoter polymorphism known to result in greater MMP-9 expression (Samochowiec et al., 2010). Conversely, cocaine abusers have less MMP-9 activity in the hippocampus, probably as a result of upregulation of RECK gene expression (Mash et al., 2007).

\section{MMPs in neuropsychiatric disorders}

The aforementioned MMP-9 promoter polymorphism also displays increased frequency in bipolar disorder but decreased frequency in schizophrenia (Rybakowski et al., 2009a,b), yet MMP-9 and TIMP-1 are markedly increased in plasma samples derived from schizophrenic patients (Domenici et al., 2010). Furthermore, a possible relationship between MMP-3 gene polymorphism and susceptibility to schizophrenia was also reported (Kucukali et al., 2009).

Data linking MMP-9 with human cognition are more equivocal. The MMP-9 promoter polymorphism is associated with altered executive function, tested using the Wisconsin Card Sorting Test, in males suffering from bipolar disorder (Rybakowski et al., 2009c) but not in healthy individuals with the same gene polymorphism (Rybakowski et al., 2009d). Similarly, another MMP-9 promoter polymorphism did not correlate with episodic memory deficits (Vassos et al., 2008). Bruno et al. (2009) found inverse correlations between global cognitive score and Mini-Mental State Examination score with MMP-9 activity, when analyzing human subjects with either $\mathrm{AD}$ or mild cognitive impairment versus no cognitive impairment. They also reported greater MMP-9 activity in the human frontal and parietal cortex in both $\mathrm{AD}$ and mild cognitive impairment brains. MMPs, MMP-9 in particular, have been shown as amyloid-degrading enzymes, and their expression is altered in $\mathrm{AD}$ victims (for review, see Nalivaeva et al., 2008).

In conclusion, the data presented herein, as well as in more in-depth reviews (Dzwonek et al., 2004; Ethell and Ethell, 2007; Michaluk and Kaczmarek, 2007; Milward et al., 2007; Agrawal et al., 2008; Mizoguchi et al., 2008; Rybakowski, 2009; Wright and Harding, 2009), strongly support a functional involvement of metzincin proteases and their inhibitors in the phenomena of synaptic plasticity. However, this area of neuroscience is still in its infancy given the immense complexity of potential proteolytic targets, including ECM and cell adhesion molecules, neurotrophins, and their receptors. Therefore, although these studies have clearly added a new dimension to our understanding of brain plasticity, additional studies are certainly warranted.

\section{Metzincins and TIMPs promote cell death in inflammatory neuropathologies}

MMPs participate in a number of pathological processes through the inflammatory disruption of the blood-brain barrier (BBB). Metastatic cancer cells, which secrete type IV collagenase (i.e., MMP-2), cross blood vessels by attacking basal lamina proteins to enter the tissues (Liotta et al., 1980). A more direct link between $\mathrm{BBB}$ disruption and endogenous MMP production was established in animals with intracerebral hemorrhage (Rosenberg et al., 1994). 


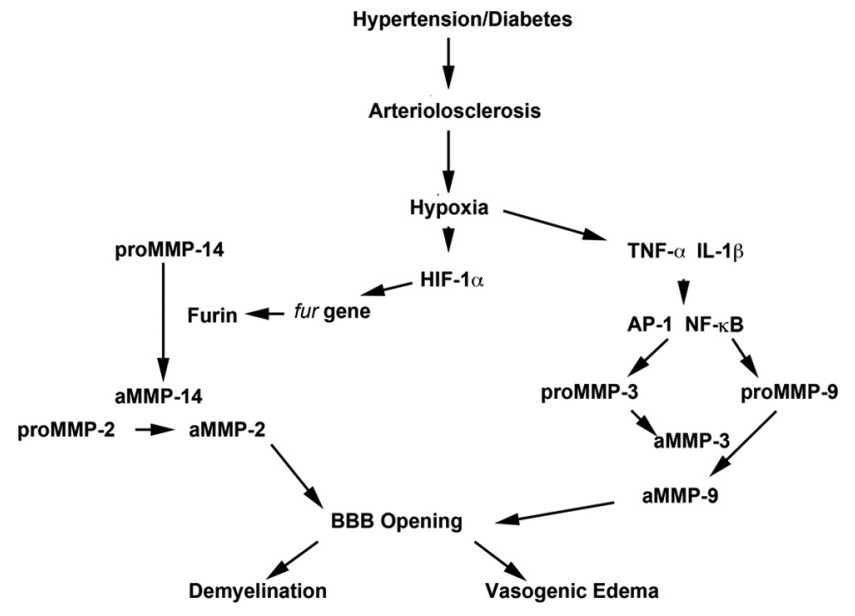

Figure 4. Role of MMP-mediated proteolysis in loss of BBB integrity. Schematic diagram of a potential mechanism for MMP-mediated demyelination in vascular cognitive impairment. Hypertension and/or diabetes causes arteriolosclerosis of the blood vessels. Hypoxic hypoperfusion of the deep white matter results in induction of HIF- $1 \alpha$ and cytokines (TNF- $\alpha$ and IL-1 $\beta$ ). HIF- $1 \alpha$ induces the fur gene and the protein furin, which activates proMMP-14 to the active form (aMMP-14). Then, aMMP-14 activates proMMP-2 to the active form of MMP-2. Cytokines induce the $\mathrm{AP}-1$ and nuclear factor $\kappa \mathrm{B}(\mathrm{NF}-\kappa \mathrm{B})$ transcription factors to produce proMMP-3 and proMMP-9. Active MMP-3 activates proMMP-9. Thus, MMPs open the BBB, leading to vasogenic edema in the white matter and demyelination.

Another early indication of a pathologic role for MMPs in BBB disruption came from studies in EAE. Administration of a broadspectrum MMP inhibitor, GM6001 ( $N$-[(2R)-2(hydroxamidocarbonylmethyl)-4-methylpantanoyl]-L-tryptophan methylamide), reduced brain damage through a mechanism that involved BBB repair (Gijbels et al., 1993). Moreover, patients with MS have increased MMP-9 levels in their CSF during an acute attack, concurrent with BBB disruption (Gijbels et al., 1992). Infectious diseases of the brain, including bacterial meningitis, viral encephalitis, and human immunodeficiency virus, are similarly associated with increased MMP-9 levels in CSF (Leppert et al., 2001). These studies and others clearly show that MMPs comprise a final common pathway for vascular injury in neuroinflammation secondary to a wide variety of brain insults (Lo et al., 2003; Yong, 2005).

MMPs in cerebral ischemia/hypoxia

Cerebral ischemia and hemorrhage initiates a complex pattern of MMP expression that is important in both the injury and repair. Shortly after the initiation of an ischemic insult in animals, basal lamina disruption is observed and is associated with MMP-2 expression (Hamann et al., 1995; Heo et al., 1999). Because MMPs are present in latent forms, mechanisms of activation must be brought into play (Fig. 4). With the onset of oxygen deprivation, hypoxia inducible factor- $1 \alpha$ (HIF- $1 \alpha$ ) activates genes that are important in adapting the brain to the hypoxic conditions, including genes involved in anaerobic metabolism, angiogenesis, red blood cell production, and growth factor production. Notably, HIF- $1 \alpha$ activates the proprotein convertase furin, which activates MMP-14, formation of a trimolecular complex between MMP-14, TIMP-2, and proMMP-2, and active MMP-2 formation. Thus, the initial phase of $\mathrm{BBB}$ disruption is mainly mediated by furin, MMP-14, and MMP-2. Ultimately, this combination affects the basal lamina and the tight junction proteins claudin and occludin (Furuse et al., 1998; Hawkins and Davis, 2005). After initial structural changes in tight junction proteins, there is resolution of $\mathrm{BBB}$ opening within several hours in the ischemic/ reperfusion suture model (Yang et al., 2007).
The second phase of BBB opening occurs after a delay of $24-48 \mathrm{~h}$ and is mediated by inducible MMPs (e.g., MMP-3 and MMP-9), initiating a more destructive phase of tissue damage. This phase takes longer to resolve than the initial opening and is accompanied by cell death in the infarct core and ongoing apoptosis in the penumbra (Lo et al., 2003). During this phase, destruction of the basal lamina increases the risk of hemorrhage, which begins as hemorrhagic transformation but, if sufficiently severe, can result in a large intracerebral hemorrhage (Hamann et al., 1995; Montaner et al., 2001). Several lines of evidence implicate MMPs in this destructive phase, including a study showing that MMP-9 KO mice have smaller strokes, less BBB damage, and improved behavior relative to their wild-type littermates (Asahi et al., 2001).

Tissue plasminogen activator (tPA) is the only Food and Drug Administration-approved stroke treatment (Anonymous, 1995), yet hemorrhage risk increases when tPA is given to patients, especially $>3 \mathrm{~h}$ after stroke onset. Several mechanisms have been suggested for this enhanced bleeding. One likely scenario is that tPA crosses an impaired BBB and once inside the brain releases plasmin, which is a major activator of MMPs (Cuzner and Opdenakker, 1999). In support of this hypothesis, tPA administration increases MMP-9 expression (Tsuji et al., 2005), and there is a strong correlation between serum MMP levels and intracerebral hemorrhage severity (Montaner et al., 2001). Another suggested mechanism involves the interaction between microglial lowdensity lipoprotein receptor-related protein 1 and tPA, which increases MMP-9 expression and activity, resulting in the degradation of claudin-5 and the development of cerebral edema (Zhang et al., 2009). The strong correlation of increased serum MMP-9 levels during stroke led to the suggestion that it may serve as a stroke biomarker (Kelly et al., 2008). However, MMP-9 detection is currently too time consuming to be clinically useful for early diagnosis.

MMP inhibitors may prove useful adjuvants to tPA in the treatment of stroke. Animals exposed to ischemia for $>5 \mathrm{~h}$ have a very high incidence of hemorrhage and many die when reperfused. Short-term use of broad-spectrum MMP inhibitors blocks $\mathrm{BBB}$ disruption, prevents tPA from entering the brain, and reduces both hemorrhage and death during reperfusion. One such agent, minocycline, a tetracycline derivative with antiinflammatory properties, blocks MMPs and prevents ischemic damage to the blood vessels (Fagan et al., 2004; Murata et al., 2008). Another agent, BB-94 [Batimastat, $(2 R, 3 S)-N^{4}$-hydroxyN1-[(1S)-2-(methylamino)-2-oxo-1-(phenylmethyl)ethyl]-2(2-methylpropyl)-3-[(2-thienylthio)methyl]butanediamide], a hydroxymate-based drug that binds to the zinc active site, effectively reduces tPA-induced injury (Lapchak et al., 2000; Pfefferkorn and Rosenberg, 2003). Although MMP inhibitors may be clinically efficacious in the treatment of acute disorders (e.g., stroke), the poor clinical trial outcomes for MMP inhibitors in cancer (discussed below) precludes its use in chronic disorders (e.g., MS, vascular dementias).

\section{MMPs in multiple sclerosis}

MS, an autoimmune CNS demyelinating disease that affects young adults, has a significant inflammatory component that is related to MMP action on the BBB and myelin (Noseworthy et al., 2000; Yong et al., 2007). Myelin can be degraded into immunogenic fragments of myelin basic protein (MBP) by the addition of MMPs, particularly MMP-9 (Chandler et al., 1995; Opdenakker et al., 2001). Furthermore, MMP-7 KO mice displayed reduced inflammation and cell entry into the brain as well as across an in vitro cell culture system, suggesting that MMP-7 may contribute 
to the inflammatory response (Buhler et al., 2009). BB-1101 (2 S-ally-N-hydroxy-3 R-isobutyl-N-(1 S-methylcar-bamoyl-2phenylethyl)-succinamide), a broad-spectrum inhibitor of MMP activity and TNF processing reduces the clinical signs and weight loss in an acute EAE model in Lewis rats (Clements et al., 1997).

Although the expression of the classic MBP transcripts is restricted to myelin-forming cells, splice variants of MBP, called Golli-MBP, can be generated by a membrane-bound MMP, MMP-25, to create similar immunogenic peptides. Autoactivation of proconvertases (PCs), furin and PC2, activates MMP-25 in macrophages, leading to immunogenic MBP fragments that are presented in the major histocompatibility complex on the cell surface. This results in T-cell activation and homing to the brain, MBP attack, and inflammation that increases macrophage infiltration and the activation of multiple MMPs, thereby contributing to additional MBP destruction (Shiryaev et al., 2009). Immunomodulation with $\beta$-interferon reduces MMPs, as does treatment with the anti-inflammatory agent minocycline; however, minocycline causes only a minor reduction in disease severity (Yong et al., 2007). In contrast, short-term use of high-dose steroids (e.g., methylprednisolone), commonly used in acute MS flares, dramatically reduces elevated MMP-9 levels in CSF and corresponds with closure of the leaky BBB, likely by blocking the proinflammatory AP-1 sites in the MMP-9 promoter (Rosenberg et al., 1996).

\section{MMPs in neurodegenerative diseases}

Because of the aging of the populations in developed countries and the improved living conditions in underdeveloped countries, a marked increase in the number of patients with vascular diseases is expected, with vascular cognitive impairment (VCI) alone or in combination with $\mathrm{AD}$ representing the largest group of dementias (Skoog et al., 1998). Biomarkers to identify these patients at an early stage are needed to better classify patients and to allow for smaller more focused clinical trials (van der Vlies et al., 2009; Wallin et al., 2010). VCI, which is the new term that encompasses all forms of vascular-related cognitive loss and includes both multi-infarct dementia and vascular dementia, is a major cause of impaired mobility, focal neurological findings, and intellectual loss in the elderly (Hachinski et al., 2006). An important link exists between vascular disease and acceleration of $\mathrm{AD}$, as demonstrated in the nun study (Snowdon et al., 1997). This link is thought to be through inflammation initiated by the presence of amyloid in the brain. Amyloid is known to increase MMP-2 and MMP-9, which could affect the blood vessels or directly damage cells (Deb et al., 1999; Yin et al., 2006). Although BBB disruption may be important in both $\mathrm{AD}$ and $\mathrm{VCI}$, direct evidence is only available in $\mathrm{VCI}$ in which abnormal BBB permeability was demonstrated by increased albumin in the CSF and contrast-enhanced magnetic resonance imaging (MRI) studies (Wallin et al., 2000; Hanyu et al., 2002; Farrall and Wardlaw, 2009; Wardlaw et al., 2009).

Small vessel disease attributable to hypertension and other vasculopathies leads to large white matter hyperintensities (LWMHs) on MRI. Autopsy studies of patients with VCI reveal MMP expressing inflammatory cells around the blood vessels, including MMP-2 in astrocytes and MMP-3 in macrophages (Rosenberg et al., 2001). Leakage of serum proteins in brains of patients with VCI suggests damage to the BBB (Akiguchi et al., 1998). Additional support for a role of MMPs in VCI comes from the finding of elevated MMP levels in the CSF of patients with VCI (Adair et al., 2004). BBB examination in patients with VCI demonstrated increased permeability in the center of LWMHs, with active leakage only in select regions. This differs from the BBB leakage seen in MS, which appears ring-like (Rosenberg, 2009b). The increased permeability found with quanti- tative methods (i.e., Patlak plots) provides a more sensitive measure of leakage than Gadolinium enhanced MRI in which images are collected a short time after contrast injection and only major changes in BBB disruption are seen (Ewing et al., 2003).

Binswanger's disease, which is characterized by intellectual impairment, gait and continence problems, and lacunar strokes (Caplan, 1995), similarly has inflammation around abnormal cerebral blood vessels. Patients with Binswanger's disease exhibit altered MMPs in the CSF and brain, suggesting this is a neuroinflammatory disease (Rosenberg, 2009a). Animal studies support an inflammatory mechanism. Bilateral carotid artery occlusion (BCAO) in the rat causes a hypoxic hypoperfusion that is proposed to be a model for VCI (Tomimoto et al., 2003). After 3 d of BCAO, vasogenic edema, increased MMP activity, and vascular damage is seen in the white matter (Sood et al., 2009). Bilateral carotid stenosis with small metal coils in the mouse leads to BBB leakage with white matter damage, which is attenuated in the MMP-2 KO mouse (Nakaji et al., 2006). The role of the various MMPs is unclear and may depend on a variety of factors. When a rat is exposed to $8 \%$ oxygen for $48 \mathrm{~h}$, simulating the altitude of Mt. Everest (7500 m), vascular permeability was increased via an MMP-9-mediated mechanism that could be blocked with an inhibitor of vascular endothelial growth factor (Bauer et al., 2010). Additional studies will be needed in rat models with hypertension to more closely simulate the human condition.

\section{Metzincins and cell death}

Multiple mechanisms likely contribute to the cell death observed in neuroinflammatory pathologies. Metzincins may regulate cell death via their traditional sheddase activities. For example, TACE releases TNF- $\alpha$ and TNF receptors from the cell membranes, whereas MMP-3 acts at the membrane to release FAS and FAS receptor. When TIMP-3 blocks the action of MMP-3 and TACE, the deathpromoting functions of FAS and TNF- $\alpha$ are facilitated (Wetzel et al., 2008). Moreover, TIMP-3 KO mice are protected from hippocampal cell apoptosis caused by a transient global ischemic injury (Walker and Rosenberg, 2009). A novel intranuclear role of MMPs in DNA damage and cell death may also contribute (Yang et al., 2010). Nuclear proteins, poly-ADP-ribose polymerase-1 (PARP-1) and x-ray cross-complementary factor 1 (XRCC1), as well as DNA repair enzymes are important in DNA fragmentation and cell apoptosis. Using a 90-min middle cerebral artery occlusion in rats, increased MMP-2 and MMP-9 activity was detected in ischemic neuronal nuclei by $3 \mathrm{~h}$ and was associated with DNA fragmentation at 24 and $48 \mathrm{~h}$ of reperfusion as well as intranuclear cleaved PARP-1 and XRCC1. However, rats treated with a broad-spectrum MMP inhibitor, BB-1101, blocked the ischemia-induced degradation of both PARP-1 and XRCC1. Free radicals may contribute to intranuclear MMP activity as shown by the elevation of oxidized DNA, apurinic/apyrimidinic sites, and 8-hydroxy-2'-deoxyguanosine, in ischemic brain cells at $3 \mathrm{~h}$ reperfusion. Again, BB-1101 markedly attenuated the early increase of oxidized DNA. Finally, tissue from stroke patients showed intranuclear MMP expression. Together, these observations suggest a novel role for MMPs in neuronal apoptosis in ischemic injuries, which may be important in other forms of non-ischemic injury.

\section{Metzincin and TIMP regulation of tumor progression and tumor suppression}

Gliomas, the most common primary CNS malignancy in adults, are histologically and molecularly heterogeneous tumors with strikingly different prognoses. Because of enhanced sensitivity to chemotherapy and radiotherapy, patients with oligodendrogliomas display a fairly good prognosis (i.e., 5 and 10 year survival 


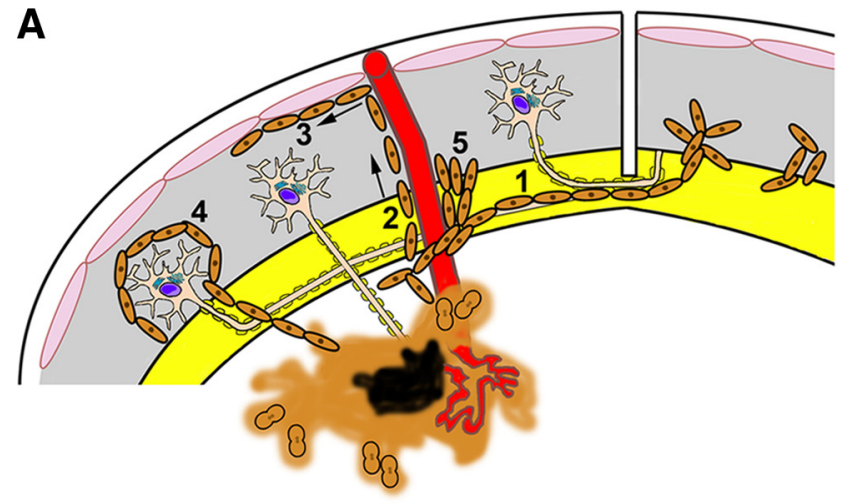

Angiogenesis

Pro: MMP-1, -2, -7, -9, -14

Anti: MMP-2, -9, -12

TIMP-2

ADAMTS-1, -8

Cell Growth

Pro: ADAM-10

MMP-2, $-3,-9,-14$
Invasion

Pro: MMP-1, -2, -3

$-7,-13,-14$

ADAMTS-4, -5

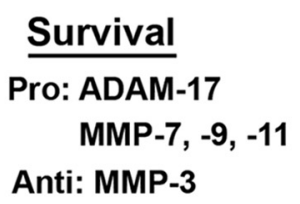

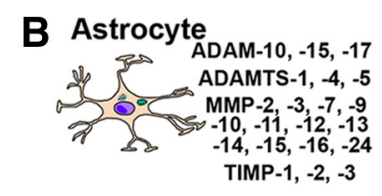

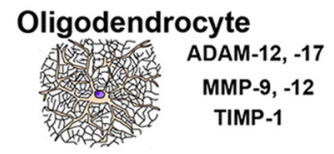

Endothelial cells

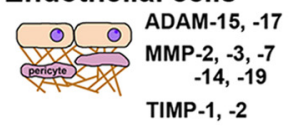

Dendritic Cell
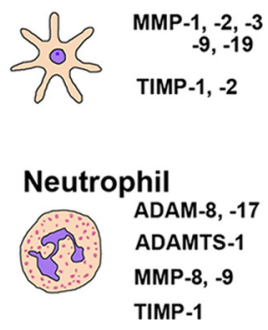

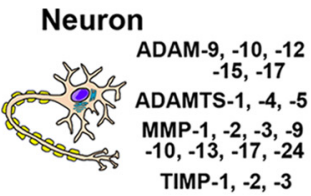

Microglia

ADAM-9, -15, -17

ADAMTS-4

MMP-1, $-2,-7$,

$-9,-12,-14$

TIMP-1, -2, -3

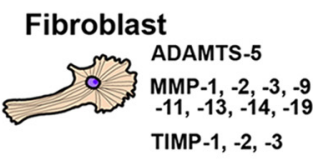

Lymphocyte
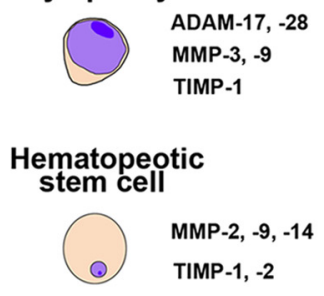

Figure 5. Role of metzincins in tumor invasion. $\boldsymbol{A}$, Primary malignant brain tumors grow as masses with irregular borders and contain regions of necrosis (black) and angiogenesis. The greatest glioma treatment challenge is tumor cell invasion. The most common route of invasion is along white matter tracts, including the corpus callosum into the contralateral hemisphere (1). Cells also migrate along the basement membrane of blood vessels (2) and spread subpially (3). Although some cells form satellites around neurons (4), others will terminate their migration at the white- gray interface (5). Metzincin proteases play multiple roles in tumor progression, with some possessing suppressive functions. $\boldsymbol{B}$, Nonexhaustive representation of metzincins and TIMPs expressed in various cell types. This presentation comes with several caveats. First, all cell types have the "potential" to express a broad spectrum of metzincins. Second, not all proteases have been profiled with reliable tools in all cell types. Third, exclusion from the table does not preclude expression by that cell type under different physiological or pathological states. Nonetheless, the table stresses the concept that metzincins/TIMPs are not only produced by tumor cells but also by resident parenchymal and stromal cells. Thus, chemotherapies must take into account the normal physiological functions within these cell types.

rates of 73 and 49\%, respectively) (Henderson and Shaw, 2001). Median survival of patients with low-grade astrocytomas [World Health Organization (WHO) grade II] is 4 years, whereas patients with anaplastic astrocytoma (WHO grade III) have a median survival of 18 months. Despite the use of multiple aggressive treatment modalities, patients with glioblastoma multiforme (GBM) (WHO grade IV astrocytoma), the most common glioma, have a median survival rate of 14 months with $<30 \%$ of patients surviving to 1 year and $<10 \%$ surviving 2 years after diagnosis (Wen and Kesari, 2008). Although many molecular targets for glioma therapy have been identified (Furnari et al., 2007; Nakada et al., 2007), sadly, this prognosis has only increased from a 10 month median survival in the past 5 years.

\section{Metzincins contribution to glioma progression}

The primary treatment challenge of astrocytomas is the insidious propensity of tumor cells to aggressively invade not only into the adjacent normal brain but to disperse to distant sites, making surgical resection palliative rather than curative (Giese et al., 2003). In marked contrast, tumors that metastasize to the brain tend to form non-infiltrating masses with well demarcated borders that are amenable to surgical resection, suggesting that factors intrinsic to glioma cells underlie their invasive potential. Astrocytomas, which preferentially originate from white matter fibrillary astrocytes, do not randomly infiltrate into the normal brain. Glioma cells show preferential migration along the leptomeninges, perivascular spread along blood vessel basement membranes, and perineuronal satellitosis around neurons in the gray matter (Fig. 5A) (Louis, 2006). However, the most frequent route of glial tumor cell invasion is along white matter tracts, with some glioma cells even crossing the corpus callosum into the contralateral hemisphere. Although these routes may simply serve as the path of least resistance, another possible explanation is that specific ECM substrates mediate glioma cell adhesion and promote migration. However, CNS myelin is a very inhibitory substrate not only for neurite outgrowth but also for the migration of several cell types, including astrocytes (Caroni and Schwab, 1988; Schwab and Caroni, 1988). Therefore, to exert their unique invasive potential, glioma cells must be able to alter their extracellular microenvironment to override the migratory inhibitory effects of myelin.

Proteases are ideal candidates to regulate tumorigenesis in that their expression is upregulated by growth factors and inflammatory cytokines that regulate proliferation, they promote cell migration via ECM destruction, and many support angiogenesis. MMP, ADAM, and ADAMTS proteases all contribute to the sculpting of the tumor microenvironment (Mochizuki and Okada, 2007; Murphy, 2008; Rocks et al., 2008; Kessenbrock et al., 2010). For review of other proteases dysregulated in glioma (e.g., the serine protease urokinase-type plasminogen activator and cysteine proteases cathepsin B, D, and L), readers are referred to the most recent reviews on the subject (Levicar et al., 2003; Rao, 2003). Multiple MMPs are upregulated in glioma, including MMP-1, MMP-7, MMP-10, MMP-11, and MMP-19 (Nuttall et al., 2003), but, not surprisingly, the most studied are the gelatinases MMP-2 and MMP-9 (Forsyth et al., 1999). Of particular relevance for pericellular proteolysis are the MT-MMPs, of which MT1-MMP, MT2-MMP, MT5-MMP, and MT6-MMP are upregulated in glioma (Llano et al., 1999; Velasco et al., 2000; Nuttall et al., 2003). Most importantly, MT1-MMP plays a key 
role in glioma cell ability to spread and migrate on myelin ( $\mathrm{Pa}-$ ganetti et al., 1988; Amberger et al., 1994; Beliën et al., 1999). ADAM-8 and ADAM-19 expression is upregulated in glioma and correlates with increased invasion, but the substrates have yet to be identified (Wildeboer et al., 2006). ADAM-10 promotes glioblastoma cell migration via $\mathrm{N}$-cadherin cleavage (Kohutek et al., 2009), whereas ADAM-12 contributes not only to glioma invasion but also proliferation through shedding of heparin-binding epidermal growth factor (Kodama et al., 2004). Hypoxia-induced ADAM-17 contributes to glioma cell invasiveness through activation of the EGF receptor (EGFR) signaling pathway (Zheng et al., 2007). Conversely, expression of the constitutively active EGFR・vIII variant in GBM is associated with upregulated MMP-1 and MMP-13 expression and increased invasion (Lal et al., 2002). ADAMTS-4 and ADAMTS-5, which are upregulated in glioma cells (Held-Feindt et al., 2006), contribute to their invasiveness by cleavage of brevican. In normal brain, brevican inhibits neurite outgrowth and cell motility (Yamada et al., 1997). Brevican is overexpressed in glioma (Jaworski et al., 1996) in which it is cleaved by ADAMTS-4/ADAMTS-5 (Matthews et al., 2000; Nakada et al., 2005). Brevican cleavage products increase invasion (Zhang et al., 1998; Viapiano et al., 2005, 2008) by promoting EGFR activation and the secretion and accumulation of fibronectin on the cell surface (Hu et al., 2008). This significant upregulation of metzincin protease expression in glioma would be expected to be associated with a compensatory increase in inhibitor expression. In keeping with their roles as tumor suppressors, TIMP-3 overexpression suppresses glioma cell infiltration (Baker et al., 1999) and RECK is downregulated in glioma (Correa et al., 2006). Other inhibitor studies are more equivocal. Some studies show that TIMP-2 and TIMP-3 expression does not correlate with tumor grade (Lampert et al., 1998; Groft et al., 2001), others show a positive correlation for TIMP-1 and TIMP-2 and aggressiveness (Nakano et al., 1995; Lampert et al., 1998; Groft et al., 2001; Nuttall et al., 2003), and others report low TIMP-1, TIMP-2, and TIMP-4 expression levels in malignant glioma (Mohanam et al., 1995; Kachra et al., 1999; Groft et al., 2001). In the presence of low TIMP expression, one would expect rampant proteolysis. However, given the dual roles of TIMPs in MMP inhibition and proMMP activation, this cannot be assumed and net proteolysis is likely dependent on the repertoire of MMPs expressed.

Both TIMPs and MMPs subserve biological activities independent of their "traditional" roles. This is best characterized for TIMP-2, which exerts effects (e.g., cell cycle arrest, angiogenesis inhibition) independent of either protease inhibition or activation via integrin $\alpha 3 \beta 1$ (Seo et al., 2003; Pérez-Martínez and Jaworski, 2005; Stetler-Stevenson, 2008a). Alternatively, TIMP-2, via interaction with MT1-MMP, could stimulate invasionpromoting ERK signaling (Sounni et al., 2010). This may partly explain the unsolved paradox that, despite being a "metalloproteinase inhibitor," high levels of TIMP-2 positively correlate with an unfavorable prognosis in many caner types (Strongin, 2010). The PEX domain of several MMPs also exerts biological activities independent of the full-length enzyme. The PEX domain of MMP-2 and MMP-9 inhibits endothelial and glioma cell proliferation and migration as well as reduces angiogenesis (Brooks et al., 1998; Bello et al., 2001; Ezhilarasan et al., 2009). Moreover, intratumoral injection of neural stem cells (NSCs) secreting MMP-2 PEX reduced tumor volume by $90 \%$ but decreased angiogenesis by $45 \%$ and cell proliferation by $24 \%$ (S. K. Kim et al., 2005). Because the NSCs migrated to the tumor boundary, it opens the possibility of using NSCs or mesenchymal stem cells
(MSCs) engineered to exploit these MMP-independent functions in glioma treatment (Kosztowski et al., 2009).

\section{Metzincins as glioma therapeutic targets}

To effectively treat gliomas, several challenges will need to be overcome. First, glioma is already invasive at time of diagnosis, and the degree of invasiveness does not necessarily correlate with the degree of malignancy in that low-grade astrocytomas display increased infiltration distance whereas GBMs display increased infiltration rates (Guthrie and Laws, 1990; Giese et al., 1996). After GBM surgical resection, glioma recurrence is universal. However, because in $>95 \%$ of the cases the tumor is within 2-3 $\mathrm{cm}$ of the resection site (Burger et al., 1983; Gaspar et al., 1992), localized anti-protease therapy may prove beneficial in preventing recurrence, thus making glioma a chronic and not fatal disease. Second, in many cases, the host-derived protease is the key contributor to invasion (Fig. 5B) (Taniwaki et al., 2007) as exemplified by the critical role played by microglial MT1-MMP expression in glioma progression (Markovic et al., 2009). Thus, treatment will also affect normal resident brain cells. Third, glioma cells migrating in vitro (Merzak et al., 1994; Giese et al., 1996) and in vivo (Dalrymple et al., 1994; Schiffer et al., 1997) show a lower proliferation rate and reduced apoptosis (Cho and Klemke, 2000; Mariani et al., 2001). Thus, inhibiting glioma cell migration will make them more susceptible to conventional cytotoxic therapy. Finally, glioma possesses multipotent cancer stem cells (CSCs) (Singh et al., 2004) that are resistant to conventional chemoradiotherapies attributable to quiescence, increased expression of multi-drug resistance transporters, more efficient DNA repair, and increased activation of survival pathways (e.g., Akt-phosphatidylinositol 3-kinase) (Stiles and Rowitch, 2008). MMPs play a role in the migration of stem cells, including targeting bone marrow-derived MSCs to glioma (Wang et al., 2006; Ho et al., 2009). Therefore, increased MMP activity may not only promote the growth and survival of CSCs but also the homing of endogenous stem cells toward tumors.

In contrast to other tumors that metastasize via hematogenous or lymphatic dissemination, glioma cells extensively invade within the brain but rarely metastasize (i.e., between 1.3 and $20 \%$ in clinical and autopsy series, respectively) ( $\mathrm{Ng}$ et al., 2005). Although short life expectancy may be a contributor to reduced extracranial dissemination, other factors likely play a role. For example, although glioma cells migrate along basement membranes, they do not intravasate into blood vessels (Bernstein and Woodard, 1995). Furthermore, even those tumor cells that enter the circulation, via the disrupted $\mathrm{BBB}$, are unable to robustly grow outside the CNS. Although the molecular basis for reduced glioma cell metastasis outside of the CNS is not known, it suggests the existence of brain-derived factors that promote cell adhesion/ retention within the CNS, perhaps via interaction with tumor stromal cells (Kessenbrock et al., 2010) or the host-tumor interface (Noël et al., 2008).

Despite the clear involvement of metzincin proteases in in vitro studies and animal models, none, little, or even adverse effects on cancer progression were reported in the initial MMP inhibitor clinical trials (Coussens et al., 2002; Pavlaki and Zucker, 2003). There is a multitude of reasons for these disappointing results. First, most inhibitors targeted the active zinc-biding site and, thus, lacked specificity. Second, the adverse musculoskeletal effects induced by MMP inhibition demonstrated the importance of MMPs in normal physiological processes. Most importantly, these trials provided evidence that at least some of the pleiotropic effects of metzincin proteases may antagonize tumor 
growth; thus, some proteases serve as tumor suppressors (Overall and Kleifeld, 2006; López-Otín and Matrisian, 2007). Several metzincin members exert anti-tumor effects, including MMP-3, MMP-8, MMP-9, MMP-11, MMP-12, MMP-19, and MMP-26, ADAM-23, and ADAMTS-1, ADAMTS-8, ADAMTS-9, ADAMTS15 , and ADAMTS-18 in various model systems. MMP-8 is a tumor suppressor (Gutiérrez-Fernández et al., 2008) whose activity is reduced by both somatic mutation (Palavalli et al., 2009) and epigenetic suppression (Chernov et al., 2010). ADAM-22 inhibits proliferation via an integrin-dependent mechanism (D'Abaco et al., 2006). ADAMTS-8, a protease with anti-angiogenic properties, is downregulated in glioma by a mechanism other than promoter hypermethylation (Dunn et al., 2006). Although ADAMTS-13 displays lower expression in glioma relative to normal brain (Böhm et al., 2003), its expression does not correlate with grade; thus, its role in glioma progression is not well understood. The only TIMP that is regarded as a tumor suppressor is TIMP-3, which is silenced via promoter hypermethylation (Gonzalez-Gomez et al., 2003; B. L. Liu et al., 2010) or microRNA-21 (Gabriely et al., 2008). These beneficial proteases/ inhibitors need to be taken into account when developing the next generation of anti-metzincin-based therapies. Furthermore, other non-MMP anti-protease therapies need to be sought (Lah et al., 2006).

The outlook for the treatment of malignant glioma is not without hope. Although improved surgical (e.g., neuroendoscopic and fluorescence-guided surgery) and radiotherapeutic approaches alone will prolong life expectancy, the most exciting advances will likely come from the development of personalized chemotherapies (Van Meir et al., 2010). The recent identification of four distinct glioblastoma subclasses (Phillips et al., 2006; Verhaak et al., 2010) emphasizes the need to create individualized therapeutic approaches. If unique protease signatures can be identified in preoperative biopsy specimens, then therapies can be based on each patient's unique molecular profile.

\section{Concluding prospective}

Metzincins and their inhibitors are clearly both foes and friends in nervous system physiopathology. However, many questions on the biology of these proteins remain open, and addressing them represents a tremendous challenge for the years to come. We still have an incomplete knowledge of the spatiotemporal pattern of expression of most metzincins and very limited knowledge of their in vivo substrates. The identification of the latter appears daunting and needs to be addressed, for example, with high-throughput proteomic approaches, if we are to better discern the physiological and pathological consequences of proteolytic cleavage. This includes a better understanding of the diversity and activity of novel bioactive molecules generated, for instance, from shedding of receptor ectodomains. Also, much remains to be learned about the subcellular localization of the proteolytically active forms of the enzymes in neural and neurovascular cells. The development and implementation of tagged probes, as specific as possible, suitable for both biochemical and microscopic techniques would be a major breakthrough to achieve this goal. What are the extent and functional relevance of intracellular and intranuclear localization of metalloproteinases that we are just starting to unveil? What signal transduction pathways are activated during intracellular and extracellular proteolytic processing? What are the other functions of non-active proteinases and inhibitors, and what proteins do they interact with at the plasma membrane? We have seen that some TIMP-mediated effects do not depend on their ability to inhibit metzincins but rather de- pend on interactions with pericellular receptors (e.g., integrins). Do metzincins elicit activities independent of proteolysis in the nervous system? The lack of proteolytic activity exhibited by some ADAMs, albeit biologically active, and activity of the MMP PEX domains suggests that this may be the case. Why the same enzyme may exert both detrimental and beneficial effects, as is, for instance, the case with MMP-9 in many respects, and why in turn do several enzymes appear to convey similar functions? Functional redundancy among members of the large metzincin family is a caveat for understanding their activities on specific substrates, and therefore the foreseeable efforts in the development of conditional $\mathrm{KO}$ mice should be a major asset in better understanding the roles of metalloproteinases. Finally, increasing our basic knowledge on the biology of the metzincin/TIMP system should improve the specificity and the efficacy of potential therapeutic strategies aiming at either inhibiting the detrimental or promoting the beneficial effects of metalloproteinase activity in the nervous system.

\section{References}

Adair JC, Charlie J, Dencoff JE, Kaye JA, Quinn JF, Camicioli RM, StetlerStevenson WG, Rosenberg GA (2004) Measurement of gelatinase B (MMP-9) in the cerebrospinal fluid of patients with vascular dementia and Alzheimer disease. Stroke 35:e159-e162.

Agrawal SM, Lau L, Yong VW (2008) MMPs in the central nervous system: where the good guys go bad. Semin Cell Dev Biol 19:42-51.

Ahmed Z, Dent RG, Leadbeater WE, Smith C, Berry M, Logan A (2005) Matrix metalloproteases: degradation of the inhibitory environment of the transected optic nerve and the scar by regenerating axons. Mol Cell Neurosci 28:64-78.

Ahmed Z, Mazibrada G, Seabright RJ, Dent RG, Berry M, Logan A (2006) TACE-induced cleavage of NgR and p75NTR in dorsal root ganglion cultures disinhibits outgrowth and promotes branching of neurites in the presence of inhibitory CNS myelin. FASEB J 20:1939-1941.

Akiguchi I, Tomimoto H, Suenaga T, Wakita H, Budka H (1998) Bloodbrain barrier dysfunction in Binswanger's disease; an immunohistochemical study. Acta Neuropathol (Berl) 95:78-84.

Amberger VR, Paganetti PA, Seulberger H, Eldering JA, Schwab ME (1994) Characterization of a membrane-bound metalloendoprotease of rat C6 glioblastoma cells. Cancer Res 54:4017-4025.

Anonymous (1995) Tissue plasminogen activator for acute ischemic stroke. The National Institute of Neurological Disorders and Stroke rt-PA Stroke Study Group. N Engl J Med 333:1581-1587.

Asahi M, Wang X, Mori T, Sumii T, Jung JC, Moskowitz MA, Fini ME, Lo EH (2001) Effects of matrix metalloproteinase-9 gene knock-out on the proteolysis of blood-brain barrier and white matter components after cerebral ischemia. J Neurosci 21:7724-7732.

Ayoub AE, Cai TQ, Kaplan RA, Luo J (2005) Developmental expression of matrix metalloproteinases 2 and 9 and their potential role in the histogenesis of the cerebellar cortex. J Comp Neurol 481:403-415.

Baba Y, Yasuda O, Takemura Y, Ishikawa Y, Ohishi M, Iwanami J, Mogi M, Doe N, Horiuchi M, Maeda N, Fukuo K, Rakugi H (2009) Timp-3 deficiency impairs cognitive function in mice. Lab Invest 89:1340-1347.

Baker AH, George SJ, Zaltsman AB, Murphy G, Newby AC (1999) Inhibition of invasion and induction of apoptotic cell death of cancer cell lines by overexpression of TIMP-3. Br J Cancer 79:1347-1355.

Bauer AT, Bürgers HF, Rabie T, Marti HH (2010) Matrix metalloproteinase-9 mediates hypoxia-induced vascular leakage in the brain via tight junction rearrangement. J Cereb Blood Flow Metab 30:837-848.

Beliën AT, Paganetti PA, Schwab ME (1999) Membrane-type 1 matrix metalloprotease (MT1-MMP) enables invasive migration of glioma cells in central nervous system white matter. J Cell Biol 144:373-384.

Bell KF, Zheng L, Fahrenholz F, Cuello AC (2008) ADAM-10 overexpression increases cortical synaptogenesis. Neurobiol Aging 29:554-565.

Bello L, Lucini V, Carrabba G, Giussani C, Machluf M, Pluderi M, Nikas D, Zhang J, Tomei G, Villani RM, Carroll RS, Bikfalvi A, Black PM (2001) Simultaneous inhibition of glioma angiogenesis, cell proliferation, and invasion by a naturally occurring fragment of human metalloproteinase-2. Cancer Res 61:8730-8736. 
Ben-Hur T, Ben-Yosef Y, Mizrachi-Kol R, Ben-Menachem O, Miller A (2006) Cytokine-mediated modulation of MMPs and TIMPs in multipotential neural precursor cells. J Neuroimmunol 175:12-18.

Bernstein JJ, Woodard CA (1995) Glioblastoma cells do not intravasate into blood vessels. Neurosurgery 36:124-132.

Bilousova TV, Dansie L, Ngo M, Aye J, Charles JR, Ethell DW, Ethell IM (2009) Minocycline promotes dendritic spine maturation and improves behavioural performance in the fragile X mouse model. J Med Genet 46:94-102.

Blobel CP, Wolfsberg TG, Turck CW, Myles DG, Primakoff P, White JM (1992) A potential fusion peptide and an integrin ligand domain in a protein active in sperm-egg fusion. Nature 356:248-252.

Böhm M, Gerlach R, Beecken WD, Scheuer T, Stier-Brück I, Scharrer I (2003) ADAMTS-13 activity in patients with brain and prostate tumors is mildly reduced, but not correlated to stage of malignancy and metastasis. Thromb Res 111:33-37.

Bovetti S, Bovolin P, Perroteau I, Puche AC (2007) Subventricular zonederived neuroblast migration to the olfactory bulb is modulated by matrix remodelling. Eur J Neurosci 25:2021-2033.

Bozdagi O, Nagy V, Kwei KT, Huntley GW (2007) In vivo roles for matrix metalloproteinase- 9 in mature hippocampal synaptic physiology and plasticity. J Neurophysiol 98:334-344.

Brew K, Nagase H (2010) The tissue inhibitors of metalloproteinases (TIMPs): An ancient family with structural and functional diversity. Biochim Biophys Acta 1803:55-71.

Bridges LC, Bowditch RD (2005) ADAM-Integrin Interactions: potential integrin regulated ectodomain shedding activity. Curr Pharm Des 11:837-847.

Brooks PC, Silletti S, von Schalscha TL, Friedlander M, Cheresh DA (1998) Disruption of angiogenesis by PEX, a noncatalytic metalloproteinase fragment with integrin binding activity. Cell 92:391-400.

Brown TE, Forquer MR, Cocking DL, Jansen HT, Harding JW, Sorg BA (2007) Role of matrix metalloproteinases in the acquisition and reconsolidation of cocaine-induced conditioned place preference. Learn Mem 14:214-223.

Brown TE, Wilson AR, Cocking DL, Sorg BA (2009) Inhibition of matrix metalloproteinase activity disrupts reconsolidation but not consolidation of a fear memory. Neurobiol Learn Mem 91:66-72.

Bruno MA, Cuello AC (2006) Activity-dependent release of precursor nerve growth factor, conversion to mature nerve growth factor, and its degradation by a protease cascade. Proc Natl Acad Sci U S A 103:6735-6740.

Bruno MA, Mufson EJ, Wuu J, Cuello AC (2009) Increased matrix metalloproteinase 9 activity in mild cognitive impairment. J Neuropathol Exp Neurol 68:1309-1318.

Buhler LA, Samara R, Guzman E, Wilson CL, Krizanac-Bengez L, Janigro D, Ethell DW (2009) Matrix metalloproteinase-7 facilitates immune access to the CNS in experimental autoimmune encephalomyelitis. BMC Neurosci 10:17.

Burger PC, Dubois PJ, Schold SC Jr, Smith KR Jr, Odom GL, Crafts DC, Giangaspero F (1983) Computerized tomographic and pathologic studies of the untreated, quiescent, and recurrent glioblastoma multiforme. J Neurosurg 58:159-169.

Butler GS, Butler MJ, Atkinson SJ, Will H, Tamura T, Schade van Westrum S, Crabbe T, Clements J, d'Ortho MP, Murphy G (1998) The TIMP2 membrane type 1 metalloproteinase "receptor" regulates the concentration and efficient activation of progelatinase A. J Biol Chem 273:871-880.

Caplan LR (1995) Binswanger's disease: revisited. Neurology 45:626-633.

Caroni P, Schwab ME (1988) Two membrane protein fractions from rat central myelin with inhibitory properties for neurite growth and fibroblast spreading. J Cell Biol 106:1281-1288.

Caterina JJ, Yamada S, Caterina NC, Longenecker G, Holmbäck K, Shi J, Yermovsky AE, Engler JA, Birkedal-Hansen H (2000) Inactivating mutation of the mouse Tissue Inhibitor of Metalloproteinases-2 (Timp-2) gene alters proMMP-2 activation. J Biol Chem 275:26416-26422.

Cazzin C, Mion S, Caldara F, Rimland JM, Domenici E (2010) Microarray analysis of cultured rat hippocampal neurons treated with brain derived neurotrophic factor. Mol Biol Rep. Advance online publication. Retrieved October 15, 2010. doi:10.1007/s11033-010-0193-0.

Chaillan FA, Rivera S, Marchetti E, Jourquin J, Werb Z, Soloway PD, Khrestchatisky M, Roman FS (2006) Involvement of tissue inhibition of metalloproteinases- 1 in learning and memory in mice. Behav Brain Res 173:191-198.
Chandler S, Coates R, Gearing A, Lury J, Wells G, Bone E (1995) Matrix metalloproteinases degrade myelin basic protein. Neurosci Lett 201:223-226.

Chernov AV, Baranovskaya S, Golubkov VS, Wakeman DR, Snyder EY, Williams R, Strongin AY (2010) Microarray-based transcriptional and epigenetic profiling of matrix metalloproteinases, collagens and related genes in cancer. J Biol Chem 285:19647-19659.

Chirco R, Liu XW, Jung KK, Kim HR (2006) Novel functions of TIMPs in cell signaling. Cancer Metastasis Rev 25:99-113.

Cho RW, Park JM, Wolff SB, Xu D, Hopf C, Kim JA, Reddy RC, Petralia RS, Perin MS, Linden DJ, Worley PF (2008) mGluR1/5-dependent longterm depression requires the regulated ectodomain cleavage of neuronal pentraxin NPR by TACE. Neuron 57:858-871.

Cho SY, Klemke RL (2000) Extracellular-regulated kinase activation and CAS/Crk coupling regulate cell migration and suppress apoptosis during invasion of the extracellular matrix. J Cell Biol 149:223-236.

Clark IM, Swingler TE, Sampieri CL, Edwards DR (2008) The regulation of matrix metalloproteinases and their inhibitors. Int J Biochem Cell Biol 40:1362-1378.

Clements JM, Cossins JA, Wells GM, Corkill DJ, Helfrich K, Wood LM, Pigott R, Stabler G, Ward GA, Gearing AJ, Miller KM (1997) Matrix metalloproteinase expression during experimental autoimmune encephalomyelitis and effects of a combined matrix metalloproteinase and tumour necrosis factor-alpha inhibitor. J Neuroimmunol 74:85-94.

Conant K, Wang Y, Szklarczyk A, Dudak A, Mattson MP, Lim ST (2010) Matrix metalloproteinase-dependent shedding of intercellular adhesion molecule-5 occurs with long-term potentiation. Neuroscience 166:508-521.

Copin JC, Gasche Y (2007) Matrix metalloproteinase-9 deficiency has no effect on glial scar formation after transient focal cerebral ischemia in mouse. Brain Res 1150:167-173.

Correa TC, Brohem CA, Winnischofer SM, da Silva Cardeal LB, Sasahara RM, Taboga SR, Sogayar MC, Maria-Engler SS (2006) Downregulation of the RECK-tumor and metastasis suppressor gene in glioma invasiveness. J Cell Biochem 99:156-167.

Coussens LM, Fingleton B, Matrisian LM (2002) Matrix metalloproteinase inhibitors and cancer: trials and tribulations. Science 295:2387-2392.

Crocker SJ, Pagenstecher A, Campbell IL (2004) The TIMPs tango with MMPs and more in the central nervous system. J Neurosci Res 75:1-11.

Cross AK, Haddock G, Stock CJ, Allan S, Surr J, Bunning RA, Buttle DJ, Woodroofe MN (2006a) ADAMTS-1 and -4 are up-regulated following transient middle cerebral artery occlusion in the rat and their expression is modulated by TNF in cultured astrocytes. Brain Res 1088:19-30.

Cross AK, Haddock G, Surr J, Plumb J, Bunning RA, Buttle DJ, Woodroofe MN (2006b) Differential expression of ADAMTS-1, -4, -5 and TIMP-3 in rat spinal cord at different stages of acute experimental autoimmune encephalomyelitis. J Autoimmun 26:16-23.

Cuadrado E, Rosell A, Borrell-Pagès M, García-Bonilla L, Hernández-Guillamon M, Ortega-Aznar A, Montaner J (2009) Matrix metalloproteinase-13 is activated and is found in the nucleus of neural cells after cerebral ischemia. J Cereb Blood Flow Metab 29:398-410.

Cuzner ML, Opdenakker G (1999) Plasminogen activators and matrix metalloproteases, mediators of extracellular proteolysis in inflammatory demyelination of the central nervous system. J Neuroimmunol 94:1-14.

D’Abaco GM, Ng K, Paradiso L, Godde NJ, Kaye A, Novak U (2006) ADAM22, expressed in normal brain but not in high-grade gliomas, inhibits cellular proliferation via the disintegrin domain. Neurosurgery 58:179-186.

Dalrymple SJ, Parisi JE, Roche PC, Ziesmer SC, Scheithauer BW, Kelly PJ (1994) Changes in proliferating cell nuclear antigen expression in glioblastoma multiforme cells along a stereotactic biopsy trajectory. Neurosurgery 35:1036-1044; discussion 1044-1045.

Deb S, Zhang JW, Gottschall PE (1999) Activated isoforms of MMP-2 are induced in U87 human glioma cells in response to $\beta$-amyloid peptide. J Neurosci Res 55:44-53.

Díaz-Rodríguez E, Cabrera N, Esparís-Ogando A, Montero JC, Pandiella A (1999) Cleavage of the TrkA neurotrophin receptor by multiple metalloproteases generates signalling-competent truncated forms. Eur J Neurosci 11:1421-1430.

Domenici E, Willé DR, Tozzi F, Prokopenko I, Miller S, McKeown A, Brittain C, Rujescu D, Giegling I, Turck CW, Holsboer F, Bullmore ET, Middleton L, Merlo-Pich E, Alexander RC, Muglia P (2010) Plasma protein bi- 
omarkers for depression and schizophrenia by multi analyte profiling of case-control collections. PLoS One 5:e9166.

Duchossoy Y, Horvat JC, Stettler O (2001) MMP-related gelatinase activity is strongly induced in scar tissue of injured adult spinal cord and forms pathways for ingrowing neurites. Mol Cell Neurosci 17:945-956.

Dunn JR, Reed JE, du Plessis DG, Shaw EJ, Reeves P, Gee AL, Warnke P, Walker C (2006) Expression of ADAMTS-8, a secreted protease with antiangiogenic properties, is downregulated in brain tumours. Br J Cancer 94:1186-1193.

Dzwonek J, Rylski M, Kaczmarek L (2004) Matrix metalloproteinases and their endogenous inhibitors in neuronal physiology of the adult brain. FEBS Lett 567:129-135.

Edwards DR, Handsley MM, Pennington CJ (2008) The ADAM metalloproteinases. Mol Aspects Med 29:258-289.

Endres K, Fahrenholz F (2010) Upregulation of the $\alpha$-secretase ADAM10 risk or reason for hope? FEBS J 277:1585-1596.

Ethell IM, Ethell DW (2007) Matrix metalloproteinases in brain development and remodeling: synaptic functions and targets. J Neurosci Res 85:2813-2823.

Ewing JR, Knight RA, Nagaraja TN, Yee JS, Nagesh V, Whitton PA, Li L, Fenstermacher JD (2003) Patlak plots of Gd-DTPA MRI data yield blood-brain transfer constants concordant with those of 14C-sucrose in areas of blood-brain opening. Magn Reson Med 50:283-292.

Ezhilarasan R, Jadhav U, Mohanam I, Rao JS, Gujrati M, Mohanam S (2009) The hemopexin domain of MMP-9 inhibits angiogenesis and retards the growth of intracranial glioblastoma xenograft in nude mice. Int J Cancer 124:306-315

Fagan SC, Edwards DJ, Borlongan CV, Xu L, Arora A, Feuerstein G, Hess DC (2004) Optimal delivery of minocycline to the brain: implication for human studies of acute neuroprotection. Exp Neurol 186:248-251.

Fager N, Jaworski DM (2000) Differential spatial distribution and temporal regulation of tissue inhibitor of metalloproteinase mRNA expression during rat central nervous system development. Mech Dev 98:105-109.

Falo MC, Fillmore HL, Reeves TM, Phillips LL (2006) Matrix metalloproteinase- 3 expression profile differentiates adaptive and maladaptive synaptic plasticity induced by traumatic brain injury. J Neurosci Res 84:768-781.

Fambrough D, Pan D, Rubin GM, Goodman CS (1996) The cell surface metalloprotease/disintegrin Kuzbanian is required for axonal extension in Drosophila. Proc Natl Acad Sci U S A 93:13233-13238.

Fanjul-Fernández M, Folgueras AR, Cabrera S, López-Otín C (2010) Matrix metalloproteinases: evolution, gene regulation and functional analysis in mouse models. Biochim Biophys Acta 1803:3-19.

Farrall AJ, Wardlaw JM (2009) Blood-brain barrier: ageing and microvascular disease - systematic review and meta-analysis. Neurobiol Aging 30:337-352.

Fisher JF, Mobashery S (2006) Recent advances in MMP inhibitor design. Cancer Metastasis Rev 25:115-136.

Forsyth PA, Wong H, Laing TD, Rewcastle NB, Morris DG, Muzik H, Leco KJ, Johnston RN, Brasher PM, Sutherland G, Edwards DR (1999) Gelatinase-A (MMP-2), gelatinase-B (MMP-9) and membrane type matrix metalloproteinase-1 (MT1-MMP) are involved in different aspects of the pathophysiology of malignant gliomas. Br J Cancer 79:1828-1835.

Frölichsthal-Schoeller P, Vescovi AL, Krekoski CA, Murphy G, Edwards DR, Forsyth P (1999) Expression and modulation of matrix metalloproteinase-2 and tissue inhibitors of metalloproteinases in human embryonic CNS stem cells. Neuroreport 10:345-351.

Furnari FB, Fenton T, Bachoo RM, Mukasa A, Stommel JM, Stegh A, Hahn WC, Ligon KL, Louis DN, Brennan C, Chin L, DePinho RA, Cavenee WK (2007) Malignant astrocytic glioma: genetics, biology, and paths to treatment. Genes Dev 21:2683-2710.

Furuse M, Fujita K, Hiiragi T, Fujimoto K, Tsukita S (1998) Claudin-1 and -2 : novel integral membrane proteins localizing at tight junctions with no sequence similarity to occludin. J Cell Biol 141:1539-1550.

Gabriely G, Wurdinger T, Kesari S, Esau CC, Burchard J, Linsley PS, Krichevsky AM (2008) MicroRNA 21 promotes glioma invasion by targeting matrix metalloproteinase regulators. Mol Cell Biol 28:5369-5380.

Galko MJ, Tessier-Lavigne M (2000) Function of an axonal chemoattractant modulated by metalloprotease activity. Science 289:1365-1367.

Gao G, Westling J, Thompson VP, Howell TD, Gottschall PE, Sandy JD (2002) Activation of the proteolytic activity of ADAMTS4 (aggrecanase-1) by C-terminal truncation. J Biol Chem 277:11034-11041.
Gaspar LE, Fisher BJ, Macdonald DR, LeBer DV, Halperin EC, Schold SC Jr, Cairncross JG (1992) Supratentorial malignant glioma: patterns of recurrence and implications for external beam local treatment. Int J Radiat Oncol Biol Phys 24:55-57.

Gaultier A, Cousin H, Darribère T, Alfandari D (2002) ADAM13 disintegrin and cysteine-rich domains bind to the second heparin-binding domain of fibronectin. J Biol Chem 277:23336-23344.

Gawlak M, Górkiewicz T, Gorlewicz A, Konopacki FA, Kaczmarek L, Wilczynski GM (2009) High resolution in situ zymography reveals matrix metalloproteinase activity at glutamatergic synapses. Neuroscience 158:167-176.

Giese A, Loo MA, Tran N, Haskett D, Coons SW, Berens ME (1996) Dichotomy of astrocytoma migration and proliferation. Int J Cancer 67:275-282.

Giese A, Bjerkvig R, Berens ME, Westphal M (2003) Cost of migration: invasion of malignant gliomas and implications for treatment. J Clin Oncol 21:1624-1636.

Gijbels K, Masure S, Carton H, Opdenakker G (1992) Gelatinase in the cerebrospinal fluid of patients with multiple sclerosis and other inflammatory neurological disorders. J Neuroimmunol 41:29-34.

Gijbels K, Proost P, Masure S, Carton H, Billiau A, Opdenakker G (1993) Gelatinase B is present in the cerebrospinal fluid during experimental autoimmune encephalomyelitis and cleaves myelin basic protein. J Neurosci Res 36:432-440.

Gonthier B, Nasarre C, Roth L, Perraut M, Thomasset N, Roussel G, Aunis D, Bagnard D (2007) Functional interaction between matrix metalloproteinase-3 and semaphorin-3C during cortical axonal growth and guidance. Cereb Cortex 17:1712-1721.

Gonthier B, Koncina E, Satkauskas S, Perraut M, Roussel G, Aunis D, Kapfhammer JP, Bagnard D (2009) A PKC-dependent recruitment of MMP-2 controls semaphorin-3A growth-promoting effect in cortical dendrites. PLoS One 4:e5099.

Gonzalez-Gomez P, Bello MJ, Arjona D, Lomas J, Alonso ME, De Campos JM, Vaquero J, Isla A, Gutierrez M, Rey JA (2003) Promoter hypermethylation of multiple genes in astrocytic gliomas. Int J Oncol 22:601-608.

Goussev S, Hsu JY, Lin Y, Tjoa T, Maida N, Werb Z, Noble-Haeusslein LJ (2003) Differential temporal expression of matrix metalloproteinases after spinal cord injury: relationship to revascularization and wound healing. J Neurosurg 99:188-197.

Greene J, Wang M, Liu YE, Raymond LA, Rosen C, Shi YE (1996) Molecular cloning and characterization of human tissue inhibitor of metalloproteinase 4. J Biol Chem 271:30375-30380.

Groft LL, Muzik H, Rewcastle NB, Johnston RN, Knäuper V, Lafleur MA, Forsyth PA, Edwards DR (2001) Differential expression and localization of TIMP-1 and TIMP-4 in human gliomas. Br J Cancer 85:55-63.

Gross J, Lapiere CM (1962) Collagenolytic activity in amphibian tissues: a tissue culture assay. Proc Natl Acad Sci U S A 48:1014-1022.

Gupta S, Li H, Sampson NS (2000) Characterization of fertilin betadisintegrin binding specificity in sperm-egg adhesion. Bioorg Med Chem 8:723-729.

Guthrie BL, Laws ER Jr (1990) Supratentorial low-grade gliomas. Neurosurg Clin N Am 1:37-48.

Gutiérrez-Fernández A, Fueyo A, Folgueras AR, Garabaya C, Pennington CJ, Pilgrim S, Edwards DR, Holliday DL, Jones JL, Span PN, Sweep FC, Puente XS, López-Otín C (2008) Matrix metalloproteinase-8 functions as a metastasis suppressor through modulation of tumor cell adhesion and invasion. Cancer Res 68:2755-2763.

Hachinski V, Iadecola C, Petersen RC, Breteler MM, Nyenhuis DL, Black SE, Powers WJ, DeCarli C, Merino JG, Kalaria RN, Vinters HV, Holtzman DM, Rosenberg GA, Wallin A, Dichgans M, Marler JR, Leblanc GG (2006) National Institute of Neurological Disorders and StrokeCanadian Stroke Network vascular cognitive impairment harmonization standards. Stroke 37:2220-2241.

Haddock G, Cross AK, Plumb J, Surr J, Buttle DJ, Bunning RA, Woodroofe MN (2006) Expression of ADAMTS-1,-4,-5 and TIMP-3 in normal and multiple sclerosis CNS white matter. Mult Scler 12:386-396.

Hamann GF, Okada Y, Fitridge R, del Zoppo GJ (1995) Microvascular basal lamina antigens disappear during cerebral ischemia and reperfusion. Stroke 26:2120-2126.

Hamel MG, Mayer J, Gottschall PE (2005) Altered production and proteolytic processing of brevican by transforming growth factor beta in cultured astrocytes. J Neurochem 93:1533-1541.

Hamel MG, Ajmo JM, Leonardo CC, Zuo F, Sandy JD, Gottschall PE (2008) Multimodal signaling by the ADAMTSs (a disintegrin and metallopro- 
teinase with thrombospondin motifs) promotes neurite extension. Exp Neurol 210:428-440.

Hanyu H, Asano T, Tanaka Y, Iwamoto T, Takasaki M, Abe K (2002) Increased blood-brain barrier permeability in white matter lesions of Binswanger's disease evaluated by contrast-enhanced MRI. Dement Geriatr Cogn Disord 14:1-6.

Hartmann D, de Strooper B, Serneels L, Craessaerts K, Herreman A, Annaert W, Umans L, Lübke T, Lena Illert A, von Figura K, Saftig P (2002) The disintegrin/metalloprotease ADAM 10 is essential for Notch signalling but not for alpha-secretase activity in fibroblasts. Hum Mol Genet 11:2615-2624.

Hattori M, Osterfield M, Flanagan JG (2000) Regulated cleavage of a contact-mediated axon repellent. Science 289:1360-1365.

Hawkins BT, Davis TP (2005) The blood-brain barrier/neurovascular unit in health and disease. Pharmacol Rev 57:173-185.

Hayashita-Kinoh H, Kinoh H, Okada A, Komori K, Itoh Y, Chiba T, Kajita M, Yana I, Seiki M (2001) Membrane-type 5 matrix metalloproteinase is expressed in differentiated neurons and regulates axonal growth. Cell Growth Differ 12:573-580.

Held-Feindt J, Paredes EB, Blömer U, Seidenbecher C, Stark AM, Mehdorn HM, Mentlein R (2006) Matrix-degrading proteases ADAMTS4 and ADAMTS5 (disintegrins and metalloproteinases with thrombospondin motifs 4 and 5) are expressed in human glioblastomas. Int J Cancer 118:55-61.

Henderson KH, Shaw EG (2001) Randomized trials of radiation therapy in adult low-grade gliomas. Semin Radiat Oncol 11:145-151.

Heo JH, Lucero J, Abumiya T, Koziol JA, Copeland BR, del Zoppo GJ (1999) Matrix metalloproteinases increase very early during experimental focal cerebral ischemia. J Cereb Blood Flow Metab 19:624-633.

Ho IA, Chan KY, Ng WH, Guo CM, Hui KM, Cheang P, Lam PY (2009) Matrix metalloproteinase 1 is necessary for the migration of human bone marrow-derived mesenchymal stem cells toward human glioma. Stem Cells 27:1366-1375.

Hsu JY, McKeon R, Goussev S, Werb Z, Lee JU, Trivedi A, Noble-Haeusslein LJ (2006) Matrix metalloproteinase-9 facilitates glial scar formation in the injured spinal cord. J Neurosci 26:9841-9850.

Hsu JY, Bourguignon LY, Adams CM, Peyrollier K, Zhang H, Fandel T, Cun CL, Werb Z, Noble-Haeusslein LJ (2008) Matrix metalloproteinase-9 facilitates glial scar formation in the injured spinal cord. J Neurosci 28:13467-13477.

Hu B, Kong LL, Matthews RT, Viapiano MS (2008) The proteoglycan brevican binds to fibronectin after proteolytic cleavage and promotes glioma cell motility. J Biol Chem 283:24848-24859.

Iba K, Albrechtsen R, Gilpin B, Fröhlich C, Loechel F, Zolkiewska A, Ishiguro K, Kojima T, Liu W, Langford JK, Sanderson RD, Brakebusch C, Fässler R, Wewer UM (2000) The cysteine-rich domain of human ADAM 12 supports cell adhesion through syndecans and triggers signaling events that lead to $\beta 1$ integrin-dependent cell spreading. J Cell Biol 149:1143-1156.

Janes PW, Saha N, Barton WA, Kolev MV, Wimmer-Kleikamp SH, Nievergall E, Blobel CP, Himanen JP, Lackmann M, Nikolov DB (2005) Adam meets Eph: an ADAM substrate recognition module acts as a molecular switch for ephrin cleavage in trans. Cell 123:291-304.

Jaworski DM (2000) Developmental regulation of membrane type-5 matrix metalloproteinase (MT5-MMP) expression in the rat nervous system. Brain Res 860:174-177.

Jaworski DM, Fager N (2000) Regulation of tissue inhibitor of metalloproteinase-3 (Timp-3) mRNA expression during rat CNS development. J Neurosci Res 61:396-408.

Jaworski DM, Kelly GM, Piepmeier JM, Hockfield S (1996) BEHAB (Brain Enriched Hyaluronan Binding) is expressed in surgical samples of glioma and in intracranial grafts of invasive glioma cell lines. Cancer Res 56:2293-2298.

Jaworski DM, Boone J, Caterina J, Soloway P, Falls WA (2005) Prepulse inhibition and fear-potentiated startle are altered in tissue inhibitor of metalloproteinase-2 (TIMP-2) knockout mice. Brain Res 1051:81-89.

Jaworski J, Biedermann IW, Lapinska J, Szklarczyk A, Figiel I, Konopka D, Nowicka D, Filipkowski RK, Hetman M, Kowalczyk A, Kaczmarek L (1999) Neuronal excitation-driven and AP-1-dependent activation of tissue inhibitor of metalloproteinases-1 gene expression in rodent hippocampus. J Biol Chem 274:28106-28112.

Jones GC, Riley GP (2005) ADAMTS proteinases: a multi-domain, multi- functional family with roles in extracellular matrix turnover and arthritis. Arthritis Res Ther 7:160-169.

Jorissen E, Prox J, Bernreuther C, Weber S, Schwanbeck R, Serneels L, Snellinx A, Craessaerts K, Thathiah A, Tesseur I, Bartsch U, Weskamp G, Blobel CP, Glatzel M, De Strooper B, Saftig P (2010) The disintegrin/metalloproteinase ADAM10 is essential for the establishment of the brain cortex. J Neurosci 30:4833-4844.

Jourquin J, Tremblay E, Décanis N, Charton G, Hanessian S, Chollet AM, Le Diguardher T, Khrestchatisky M, Rivera S (2003) Neuronal activitydependent increase of net matrix metalloproteinase activity is associated with MMP-9 neurotoxicity after kainate. Eur J Neurosci 18:1507-1517.

Jourquin J, Tremblay E, Bernard A, Charton G, Chaillan FA, Marchetti E, Roman FS, Soloway PD, Dive V, Yiotakis A, Khrestchatisky M, Rivera S (2005) Tissue inhibitor of metalloproteinases-1 (TIMP-1) modulates neuronal death, axonal plasticity, and learning and memory. Eur J Neurosci 22:2569-2578.

Jung KM, Tan S, Landman N, Petrova K, Murray S, Lewis R, Kim PK, Kim DS, Ryu SH, Chao MV, Kim TW (2003) Regulated intramembrane proteolysis of the $\mathrm{p} 75$ neurotrophin receptor modulates its association with the TrkA receptor. J Biol Chem 278:42161-42169.

Jungers KA, Le Goff C, Somerville RP, Apte SS (2005) Adamts9 is widely expressed during mouse embryo development. Gene Expr Patterns 5:609-617.

Kachra Z, Beaulieu E, Delbecchi L, Mousseau N, Berthelet F, Moumdjian R, Del Maestro R, Béliveau R (1999) Expression of matrix metalloproteinases and their inhibitors in human brain tumors. Clin Exp Metastasis 17:555-566.

Kaczmarek L, Lapinska-Dzwonek J, Szymczak S (2002) Matrix metalloproteinases in the adult brain physiology: a link between c-Fos, AP-1 and remodeling of neuronal connections? EMBO J 21:6643-6648.

Kelly PJ, Morrow JD, Ning M, Koroshetz W, Lo EH, Terry E, Milne GL, Hubbard J, Lee H, Stevenson E, Lederer M, Furie KL (2008) Oxidative stress and matrix metalloproteinase-9 in acute ischemic stroke: the Biomarker Evaluation for Antioxidant Therapies in Stroke (BEAT-Stroke) study. Stroke 39:100-104.

Kessenbrock K, Plaks V, Werb Z (2010) Matrix metalloproteinases: regulators of the tumor microenvironment. Cell 141:52-67.

Kim GW, Kim HJ, Cho KJ, Kim HW, Cho YJ, Lee BI (2009) The role of MMP-9 in integrin-mediated hippocampal cell death after pilocarpineinduced status epilepticus. Neurobiol Dis 36:169-180.

Kim HJ, Fillmore HL, Reeves TM, Phillips LL (2005) Elevation of hippocampal MMP-3 expression and activity during trauma-induced synaptogenesis. Exp Neurol 192:60-72.

Kim SK, Cargioli TG, Machluf M, Yang W, Sun Y, Al-Hashem R, Kim SU, Black PM, Carroll RS (2005) PEX-producing human neural stem cells inhibit tumor growth in a mouse glioma model. Clin Cancer Res 11:5965-5970.

Kim YS, Kim SS, Cho JJ, Choi DH, Hwang O, Shin DH, Chun HS, Beal MF, Joh TH (2005) Matrix metalloproteinase-3: a novel signaling proteinase from apoptotic neuronal cells that activates microglia. J Neurosci 25:3701-3711.

Knapska E, Walasek G, Nikolaev E, Neuhäusser-Wespy F, Lipp HP, Kaczmarek L, Werka T (2006) Differential involvement of the central amygdala in appetitive versus aversive learning. Learn Mem 13:192-200.

Kodama T, Ikeda E, Okada A, Ohtsuka T, Shimoda M, Shiomi T, Yoshida K, Nakada M, Ohuchi E, Okada Y (2004) ADAM12 is selectively overexpressed in human glioblastomas and is associated with glioblastoma cell proliferation and shedding of heparin-binding epidermal growth factor. Am J Pathol 165:1743-1753.

Kohutek ZA, diPierro CG, Redpath GT, Hussaini IM (2009) ADAM-10mediated $\mathrm{N}$-cadherin cleavage is protein kinase $\mathrm{C}-\alpha$ dependent and promotes glioblastoma cell migration. J Neurosci 29:4605-4615.

Komori K, Nonaka T, Okada A, Kinoh H, Hayashita-Kinoh H, Yoshida N, Yana I, Seiki M (2004) Absence of mechanical allodynia and A $\beta$-fiber sprounting after sciatic nerve injury in mice lacking membrane-type 5 matrix metalloproteinase. FEBS Lett 557:125-128.

Konopacki FA, Rylski M, Wilczek E, Amborska R, Detka D, Kaczmarek L, Wilczynski GM (2007) Synaptic localization of seizure-induced matrix metalloproteinase-9 mRNA. Neuroscience 150:31-39.

Kosztowski T, Zaidi HA, Quiñones-Hinojosa A (2009) Applications of neural and mesenchymal stem cells in the treatment of gliomas. Expert Rev Anticancer Ther 9:597-612.

Kucukali CI, Aydin M, Ozkok E, Bilge E, Orhan N, Zengin A, Kara I (2009) 
Do schizophrenia and bipolar disorders share a common disease susceptibility variant at the MMP3 gene? Prog Neuropsychopharmacol Biol Psychiatry 33:557-561.

Kuno K, Kanada N, Nakashima E, Fujiki F, Ichimura F, Matsushima K (1997) Molecular cloning of a gene encoding a new type of metalloproteinasedisintegrin family protein with thrombospondin motifs as an inflammation associated gene. J Biol Chem 272:556-562.

Kuo CT, Jan LY, Jan YN (2005) Dendrite-specific remodeling of Drosophila sensory neurons requires matrix metalloproteases, ubiquitin-proteasome, and ecdysone signaling. Proc Natl Acad Sci U S A 102:15230-15235.

Lah TT, Durán Alonso MB, Van Noorden CJ (2006) Antiprotease therapy in cancer: hot or not? Expert Opin Biol Ther 6:257-279.

Lal A, Glazer CA, Martinson HM, Friedman HS, Archer GE, Sampson JH, Riggins GJ (2002) Mutant epidermal growth factor receptor upregulates molecular effectors of tumor invasion. Cancer Res 62:3335-3339.

Lampert K, Machein U, Machein MR, Conca W, Peter HH, Volk B (1998) Expression of matrix metalloproteinases and their tissue inhibitors in human brain tumors. Am J Pathol 153:429-437.

Lapchak PA, Chapman DF, Zivin JA (2000) Metalloproteinase inhibition reduces thrombolytic (tissue plasminogen activator)-induced hemorrhage after thromboembolic stroke. Stroke 31:3034-3040.

Larsen PH, Wells JE, Stallcup WB, Opdenakker G, Yong VW (2003) Matrix metalloproteinase- 9 facilitates remyelination in part by processing the inhibitory NG2 proteoglycan. J Neurosci 23:11127-11135.

Larsen PH, DaSilva AG, Conant K, Yong VW (2006) Myelin formation during development of the CNS is delayed in matrix metalloproteinase- 9 and -12 null mice. J Neurosci 26:2207-2214

Leco KJ, Khokha R, Pavloff N, Hawkes SP, Edwards DR (1994) Tissue inhibitor of metalloproteinases-3 (TIMP-3) is an extracellular matrixassociated protein with a distinctive pattern of expression in mouse cells and tissues. J Biol Chem 269:9352-9360.

Lee R, Kermani P, Teng KK, Hempstead BL (2001) Regulation of cell survival by secreted proneurotrophins. Science 294:1945-1948.

Lee SR, Kim HY, Rogowska J, Zhao BQ, Bhide P, Parent JM, Lo EH (2006) Involvement of matrix metalloproteinase in neuroblast cell migration from the subventricular zone after stroke. J Neurosci 26:3491-3495.

Lehmann HC, Köhne A, Bernal F, Jangouk P, Meyer Zu Hörste G, Dehmel T, Hartung HP, Previtali SC, Kieseier BC (2009) Matrix metalloproteinase-2 is involved in myelination of dorsal root ganglia neurons. Glia 57:479-489.

Leppert D, Lindberg RL, Kappos L, Leib SL (2001) Matrix metalloproteinases: multifunctional effectors of inflammation in multiple sclerosis and bacterial meningitis. Brain Res Rev 36:249-257.

Levicar N, Nuttall RK, Lah TT, Nutall RK (2003) Proteases in brain tumour progression. Acta Neurochirurgica 145:825-838.

Liotta LA, Tryggvason K, Garbisa S, Hart I, Foltz CM, Shafie S (1980) Metastatic potential correlates with enzymatic degradation of basement membrane collagen. Nature 284:67-68.

Liu BL, Cheng JX, Zhang W, Zhang X, Wang R, Lin H, Huo JL, Cheng H (2010) Quantitative detection of multiple gene promoter hypermethylation in tumor tissue, serum, and cerebrospinal fluid predicts prognosis of malignant gliomas. Neuro Oncol 12:540-548.

Liu LT, Chang HC, Chiang LC, Hung WC (2003) Histone deacetylase inhibitor up-regulates RECK to inhibit MMP-2 activation and cancer cell invasion. Cancer Res 63:3069-3072.

Liu WT, Han Y, Liu YP, Song AA, Barnes B, Song XJ (2010) Spinal matrix metalloproteinase- 9 contributes to physical dependence on morphine in mice. J Neurosci 30:7613-7623.

Llano E, Pendás AM, Freije JP, Nakano A, Knäuper V, Murphy G, López-Otin C (1999) Identification and characterization of human MT5-MMP, a new membrane-bound activator of progelatinase A overexpressed in brain tumors. Cancer Res 59:2570-2576.

Lo EH, Dalkara T, Moskowitz MA (2003) Mechanisms, challenges and opportunities in stroke. Nat Rev Neurosci 4:399-415.

López-Otín C, Matrisian LM (2007) Emerging roles of proteases in tumour suppression. Nat Rev Cancer 7:800-808.

Louis DN (2006) Molecular pathology of malignant gliomas. Annu Rev Pathol 1:97-117.

Machida CM, Scott JD, Ciment G (1991) NGF-induction of the metalloproteinase-transin/stromelysin in PC12 cells: involvement of multiple protein kinases. J Cell Biol 114:1037-1048.

Mariani L, Beaudry C, McDonough WS, Hoelzinger DB, Demuth T, Ross KR,
Berens T, Coons SW, Watts G, Trent JM, Wei JS, Giese A, Berens ME (2001) Glioma cell motility is associated with reduced transcription of proapoptotic and proliferation genes: a cDNA microarray analysis. J Neurooncol 53:161-176.

Markovic DS, Vinnakota K, Chirasani S, Synowitz M, Raguet H, Stock K, Sliwa M, Lehmann S, Kälin R, van Rooijen N, Holmbeck K, Heppner FL, Kiwit J, Matyash V, Lehnardt S, Kaminska B, Glass R, Kettenmann H (2009) Gliomas induce and exploit microglial MT1-MMP expression for tumor expansion. Proc Natl Acad Sci U S A 106:12530-12535.

Mash DC, ffrench-Mullen J, Adi N, Qin Y, Buck A, Pablo J (2007) Gene expression in human hippocampus from cocaine abusers identifies genes which regulate extracellular matrix remodeling. PLoS One 2:e1187.

Mateos S, Calothy G, Lamballe F (2003) The noncatalytic TrkCNC2 receptor is cleaved by metalloproteases upon neurotrophin-3 stimulation. Oncogene 22:740-745.

Matthews RT, Gary SC, Zerillo C, Pratta M, Solomon K, Arner EC, Hockfield S (2000) Brain-enriched hyaluronan binding (BEHAB)/brevican cleavage in a glioma cell line is mediated by a disintegrin and metalloproteinase with thrombospondin motifs (ADAMTS) family member. J Biol Chem 275:22695-22703.

Mayer J, Hamel MG, Gottschall PE (2005) Evidence for proteolytic cleavage of brevican by the ADAMTSs in the dentate gyrus after excitotoxic lesion of the mouse entorhinal cortex. BMC Neurosci 6:52.

McCawley LJ, Matrisian LM (2001) Matrix metalloproteinases: they're not just for matrix anymore! Curr Opin Cell Biol 13:534-540.

Meighan PC, Meighan SE, Davis CJ, Wright JW, Harding JW (2007) Effects of matrix metalloproteinase inhibition on short- and long-term plasticity of schaffer collateral/CA1 synapses. J Neurochem 102:2085-2096.

Meighan SE, Meighan PC, Choudhury P, Davis CJ, Olson ML, Zornes PA, Wright JW, Harding JW (2006) Effects of extracellular matrix-degrading proteases matrix metalloproteinases 3 and 9 on spatial learning and synaptic plasticity. J Neurochem 96:1227-1241.

Melendez-Zajgla J, Del Pozo L, Ceballos G, Maldonado V (2008) Tissue inhibitor of metalloproteinases-4. The road less traveled. Mol Cancer $7: 85$.

Merzak A, McCrea S, Koocheckpour S, Pilkington GJ (1994) Control of human glioma cell growth, migration and invasion in vitro by transforming growth factor $\beta 1$. Br J Cancer 70:199-203.

Michaluk P, Kaczmarek L (2007) Matrix metalloproteinase-9 in glutamatedependent adult brain function and dysfunction. Cell Death Differ 14:1255-1258.

Michaluk P, Kolodziej L, Mioduszewska B, Wilczynski GM, Dzwonek J, Jaworski J, Gorecki DC, Ottersen OP, Kaczmarek L (2007) $\beta$-dystroglycan as a target for MMP-9, in response to enhanced neuronal activity. J Biol Chem 282:16036-16041.

Michaluk P, Mikasova L, Groc L, Frischknecht R, Choquet D, Kaczmarek L (2009) Matrix metalloproteinase-9 controls NMDA receptor surface diffusion through integrin $\beta 1$ signaling. J Neurosci 29:6007-6012.

Miguel RF, Pollak A, Lubec G (2005) Metalloproteinase ADAMTS-1 but not ADAMTS-5 is manifold overexpressed in neurodegenerative disorders as Down syndrome, Alzheimer's and Pick's disease. Brain Res Mol Brain Res 133:1-5.

Milward EA, Fitzsimmons C, Szklarczyk A, Conant K (2007) The matrix metalloproteinases and CNS plasticity: an overview. J Neuroimmunol 187:9-19.

Mitchell KJ, Pinson KI, Kelly OG, Brennan J, Zupicich J, Scherz P, Leighton PA, Goodrich LV, Lu X, Avery BJ, Tate P, Dill K, Pangilinan E, Wakenight P, Tessier-Lavigne M, Skarnes WC (2001) Functional analysis of secreted and transmembrane proteins critical to mouse development. Nat Genet 28:241-249.

Mizoguchi H, Yamada K, Mouri A, Niwa M, Mizuno T, Noda Y, Nitta A, Itohara S, Banno Y, Nabeshima T (2007a) Role of matrix metalloproteinase and tissue inhibitor of MMP in methamphetamine-induced behavioral sensitization and reward: implications for dopamine receptor down-regulation and dopamine release. J Neurochem 102:1548-1560.

Mizoguchi H, Yamada K, Niwa M, Mouri A, Mizuno T, Noda Y, Nitta A, Itohara S, Banno Y, Nabeshima T (2007b) Reduction of methamphetamineinduced sensitization and reward in matrix metalloproteinase-2 and -9deficient mice. J Neurochem 100:1579-1588.

Mizoguchi H, Yamada K, Nabeshima T (2008) Neuropsychotoxicity of abused drugs: involvement of matrix metalloproteinase- 2 and -9 and tissue inhibitor of matrix metalloproteinase-2 in methamphetamine- 
induced behavioral sensitization and reward in rodents. J Pharmacol Sci 106:9-14.

Mochizuki S, Okada Y (2007) ADAMs in cancer cell proliferation and progression. Cancer Sci 98:621-628.

Mohanam S, Wang SW, Rayford A, Yamamoto M, Sawaya R, Nakajima M, Liotta LA, Nicolson GL, Stetler-Stevenson WG, Rao JS (1995) Expression of tissue inhibitors of metalloproteinases: negative regulators of human glioblastoma invasion in vivo. Clin Exp Metastasis 13:57-62.

Montaner J, Alvarez-Sabín J, Molina CA, Anglés A, Abilleira S, Arenillas J, Monasterio J (2001) Matrix metalloproteinase expression is related to hemorrhagic transformation after cardioembolic stroke. Stroke 32:2762-2767.

Morrison CJ, Butler GS, Bigg HF, Roberts CR, Soloway PD, Overall CM (2001) Cellular activation of MMP-2 (gelatinase A) by MT2-MMP occurs via a TIMP-2-independent pathway. J Biol Chem 276:47402-47410.

Muir D (1994) Metalloproteinase-dependent neurite outgrowth within a synthetic extracellular matrix is induced by nerve growth factor. Exp Cell Res 210:243-252.

Muraguchi T, Takegami Y, Ohtsuka T, Kitajima S, Chandana EP, Omura A, Miki T, Takahashi R, Matsumoto N, Ludwig A, Noda M, Takahashi C (2007) RECK modulates Notch signaling during cortical neurogenesis by regulating ADAM10 activity. Nat Neurosci 10:838-845.

Murata Y, Rosell A, Scannevin RH, Rhodes KJ, Wang X, Lo EH (2008) Extension of the thrombolytic time window with minocycline in experimental stroke. Stroke 39:3372-3377.

Murphy G (2008) The ADAMs: signalling scissors in the tumour microenvironment. Nat Rev Cancer 8:929-941.

Nagy V, Bozdagi O, Matynia A, Balcerzyk M, Okulski P, Dzwonek J, Costa RM, Silva AJ, Kaczmarek L, Huntley GW (2006) Matrix metalloproteinase-9 is required for hippocampal late-phase long-term potentiation and memory. J Neurosci 26:1923-1934.

Nagy V, Bozdagi O, Huntley GW (2007) The extracellular protease matrix metalloproteinase- 9 is activated by inhibitory avoidance learning and required for long-term memory. Learn Mem 14:655-664.

Nakada M, Miyamori H, Kita D, Takahashi T, Yamashita J, Sato H, Miura R, Yamaguchi Y, Okada Y (2005) Human glioblastomas overexpress ADAMTS-5 that degrades brevican. Acta Neuropathol 110:239-246.

Nakada M, Nakada S, Demuth T, Tran NL, Hoelzinger DB, Berens ME (2007) Molecular targets of glioma invasion. Cell Mol Life Sci 64:458-478.

Nakaji K, Ihara M, Takahashi C, Itohara S, Noda M, Takahashi R, Tomimoto H (2006) Matrix metalloproteinase-2 plays a critical role in the pathogenesis of white matter lesions after chronic cerebral hypoperfusion in rodents. Stroke 37:2816-2823.

Nakamura H, Fujii Y, Inoki I, Sugimoto K, Tanzawa K, Matsuki H, Miura R, Yamaguchi Y, Okada Y (2000) Brevican is degraded by matrix metalloproteinases and aggrecanase-1 (ADAMTS4) at different sites. J Biol Chem 275:38885-38890

Nakano A, Tani E, Miyazaki K, Yamamoto Y, Furuyama J (1995) Matrix metalloproteinases and tissue inhibitors of metalloproteinases in human gliomas. J Neurosurg 83:298-307.

Nalivaeva NN, Fisk LR, Belyaev ND, Turner AJ (2008) Amyloid-degrading enzymes as therapeutic targets in Alzheimer's disease. Curr Alzheimer Res $5: 212-224$.

Nedivi E, Hevroni D, Naot D, Israeli D, Citri Y (1993) Numerous candidate plasticity-related genes revealed by differential cDNA cloning. Nature 363:718-722.

Ng WH, Yeo TT, Kaye AH (2005) Spinal and extracranial metastatic dissemination of malignant glioma. J Clin Neurosci 12:379-382.

Niewiarowski S, McLane MA, Kloczewiak M, Stewart GJ (1994) Disintegrins and other naturally occurring antagonists of platelet fibrinogen receptors. Semin Hematol 31:289-300.

Noël A, Jost M, Maquoi E (2008) Matrix metalloproteinases at cancer tumor-host interface. Semin Cell Dev Biol 19:52-60.

Noseworthy JH, Lucchinetti C, Rodriguez M, Weinshenker BG (2000) Multiple sclerosis. N Engl J Med 343:938-952.

Nuttall RK, Pennington CJ, Taplin J, Wheal A, Yong VW, Forsyth PA, Edwards DR (2003) Elevated membrane-type matrix metalloproteinases in gliomas revealed by profiling proteases and inhibitors in human cancer cells. Mol Cancer Res 1:333-345.

Ogata Y, Enghild JJ, Nagase H (1992) Matrix metalloproteinase 3 (strome- lysin) activates the precursor for the human matrix metalloproteinase 9. J Biol Chem 267:3581-3584

Ogier C, Creidy R, Boucraut J, Soloway PD, Khrestchatisky M, Rivera S (2005) Astrocyte reactivity to Fas activation is attenuated in TIMP-1 deficient mice, an in vitro study. BMC Neurosci 6:68.

Ogier C, Bernard A, Chollet AM, LE Diguardher T, Hanessian S, Charton G, Khrestchatisky M, Rivera S (2006) Matrix metalloproteinase-2 (MMP-2) regulates astrocyte motility in connection with the actin cytoskeleton and integrins. Glia 54:272-284.

Oh J, Takahashi R, Kondo S, Mizoguchi A, Adachi E, Sasahara RM, Nishimura S, Imamura Y, Kitayama H, Alexander DB, Ide C, Horan TP, Arakawa T, Yoshida $\mathrm{H}$, Nishikawa S, Itoh Y, Seiki M, Itohara S, Takahashi C, Noda M (2001) The membrane-anchored MMP inhibitor RECK is a key regulator of extracellular matrix integrity and angiogenesis. Cell 107:789-800.

Okulski P, Jay TM, Jaworski J, Duniec K, Dzwonek J, Konopacki FA, Wilczynski GM, Sánchez-Capelo A, Mallet J, Kaczmarek L (2007) TIMP-1 abolishes MMP-9-dependent long-lasting long-term potentiation in the prefrontal cortex. Biol Psychiatry 62:359-362.

Olson ML, Meighan PC, Brown TE, Asay AL, Benoist CC, Harding JW, Wright JW (2008) Hippocampal MMP-3 elevation is associated with passive avoidance conditioning. Regul Pept 146:19-25.

Opdenakker G, Van den Steen PE, Van Damme J (2001) Gelatinase B: a tuner and amplifier of immune functions. Trends Immunol 22:571-579.

Ould-yahoui A, Tremblay E, Sbai O, Ferhat L, Bernard A, Charrat E, Gueye Y, Lim NH, Brew K, Risso JJ, Dive V, Khrestchatisky M, Rivera S (2009) A new role for TIMP-1 in modulating neurite outgrowth and morphology of cortical neurons. PLoS One 4:e8289.

Overall CM, Kleifeld O (2006) Tumour microenvironment - opinion: validating matrix metalloproteinases as drug targets and anti-targets for cancer therapy. Nat Rev Cancer 6:227-239.

Paganetti PA, Caroni P, Schwab ME (1988) Glioblastoma infiltration into central nervous system tissue in vitro: involvement of a metalloprotease. J Cell Biol 107:2281-2291.

Page-McCaw A, Ewald AJ, Werb Z (2007) Matrix metalloproteinases and the regulation of tissue remodelling. Nat Rev Mol Cell Biol 8:221-233.

Palavalli LH, Prickett TD, Wunderlich JR, Wei X, Burrell AS, Porter-Gill P, Davis S, Wang C, Cronin JC, Agrawal NS, Lin JC, Westbroek W, Hoogstraten-Miller S, Molinolo AA, Fetsch P, Filie AC, O'Connell MP, Banister CE, Howard JD, Buckhaults P, Weeraratna AT, Brody LC, Rosenberg SA, Samuels Y (2009) Analysis of the matrix metalloproteinase family reveals that MMP8 is often mutated in melanoma. Nat Genet 41:518-520.

Pastrana E, Moreno-Flores MT, Gurzov EN, Avila J, Wandosell F, Diaz-Nido J (2006) Genes associated with adult axon regeneration promoted by olfactory ensheathing cells: a new role for matrix metalloproteinase 2. J Neurosci 26:5347-5359.

Pavlaki M, Zucker S (2003) Matrix metalloproteinase inhibitors (MMPIs): the beginning of phase I or the termination of phase III clinical trials. Cancer Metastasis Rev 22:177-203.

Pérez-Martínez L, Jaworski DM (2005) Tissue inhibitor of metalloproteinase-2 promotes neuronal differentiation by acting as an anti-mitogenic signal. J Neurosci 25:4917-4929.

Pfefferkorn T, Rosenberg GA (2003) Closure of the blood-brain barrier by matrix metalloproteinase inhibition reduces rtPA-mediated mortality in cerebral ischemia with delayed reperfusion. Stroke 34:2025-2030.

Phillips HS, Kharbanda S, Chen R, Forrest WF, Soriano RH, Wu TD, Misra A, Nigro JM, Colman H, Soroceanu L, Williams PM, Modrusan Z, Feuerstein BG, Aldape K (2006) Molecular subclasses of high-grade glioma predict prognosis, delineate a pattern of disease progression, and resemble stages in neurogenesis. Cancer Cell 9:157-173.

Porter S, Clark IM, Kevorkian L, Edwards DR (2005) The ADAMTS metalloproteinases. Biochem J 386:15-27.

Postina R, Schroeder A, Dewachter I, Bohl J, Schmitt U, Kojro E, Prinzen C, Endres K, Hiemke C, Blessing M, Flamez P, Dequenne A, Godaux E, van Leuven F, Fahrenholz F (2004) A disintegrin-metalloproteinase prevents amyloid plaque formation and hippocampal defects in an Alzheimer disease mouse model. J Clin Invest 113:1456-1464.

Pruessmeyer J, Ludwig A (2009) The good, the bad and the ugly substrates for ADAM10 and ADAM17 in brain pathology, inflammation and cancer. Semin Cell Dev Biol 20:164-174

Puente XS, Sánchez LM, Overall CM, López-Otín C (2003) Human and 
mouse proteases: a comparative genomic approach. Nat Rev Genet 4:544-558.

Ranasinghe HS, Williams CE, Christophidis LJ, Mitchell MD, Fraser M, Scheepens A (2009) Proteolytic activity during cortical development is distinct from that involved in hypoxic ischemic injury. Neuroscience 158:732-744.

Rao JS (2003) Molecular mechanisms of glioma invasiveness: the role of proteases. Nat Rev Cancer 3:489-501.

Reeves TM, Prins ML, Zhu J, Povlishock JT, Phillips LL (2003) Matrix metalloproteinase inhibition alters functional and structural correlates of deafferentation-induced sprouting in the dentate gyrus. J Neurosci 23:10182-10189.

Reid MJ, Cross AK, Haddock G, Allan SM, Stock CJ, Woodroofe MN, Buttle DJ, Bunning RA (2009) ADAMTS-9 expression is up-regulated following transient middle cerebral artery occlusion (tMCAo) in the rat. Neurosci Lett 452:252-257.

Rivera S, Tremblay E, Timsit S, Canals O, Ben-Ari Y, Khrestchatisky M (1997) Tissue inhibitor of metalloproteinases-1 (TIMP-1) is differentially induced in neurons and astrocytes after seizures: evidence for developmental, immediate early gene, and lesion response. J Neurosci 17:4223-4235.

Rocks N, Paulissen G, El Hour M, Quesada F, Crahay C, Gueders M, Foidart JM, Noel A, Cataldo D (2008) Emerging roles of ADAM and ADAMTS metalloproteinases in cancer. Biochimie 90:369-379.

Rodríguez D, Morrison CJ, Overall CM (2010) Matrix metalloproteinases: What do they not do? New substrates and biological roles identified by murine models and proteomics. Biochim Biophys Acta 1803:39-54.

Rosenberg GA (2002) Matrix metalloproteinases and neuroinflammation in multiple sclerosis. Neuroscientist 8:586-595.

Rosenberg GA (2009a) Matrix metalloproteinases and their multiple roles in neurodegenerative diseases. Lancet Neurology 8:205-216.

Rosenberg GA (2009b) Inflammation and white matter damage in vascular cognitive impairment. Stroke 40:S20-S23.

Rosenberg GA, Dencoff JE, McGuire PG, Liotta LA, Stetler-Stevenson WG (1994) Injury-induced 92-kDa gelatinase and urokinase expression in rat brain. Lab Invest 71:417-422.

Rosenberg GA, Dencoff JE, Correa N Jr, Reiners M, Ford CC (1996) Effect of steroids on CSF matrix metalloproteinases in multiple sclerosis: relation to blood-brain barrier injury. Neurology 46:1626-1632.

Rosenberg GA, Sullivan N, Esiri MM (2001) White matter damage is assoiciated with matrix metalloproteinases in vascular dementia. Stroke 32:1162-1168.

Rybakowski JK (2009) Matrix Metalloproteinase-9 (MMP9)-a mediating enzyme in cardiovascular disease, cancer, and neuropsychiatric disorders. Cardiovasc Psychiatry Neurol 2009:904836.

Rybakowski JK, Skibinska M, Kapelski P, Kaczmarek L, Hauser J (2009a) Functional polymorphism of the matrix metalloproteinase-9 (MMP-9) gene in schizophrenia. Schizophr Res 109:90-93.

Rybakowski JK, Skibinska M, Leszczynska-Rodziewicz A, Kaczmarek L, Hauser J (2009b) Matrix metalloproteinase-9 gene and bipolar mood disorder. Neuromolecular Med 11:128-132.

Rybakowski JK, Skibinska M, Leszczynska-Rodziewicz A, Kaczmarek L, Hauser J (2009c) Matrix metalloproteinase-9 gene modulates prefrontal cognition in bipolar men. Psychiatr Genet 19:108-109.

Rybakowski JK, Borkowska A, Skibinska M, Kaczmarek L, Hauser J (2009d) The-1562 C/T polymorphism of the matrix metalloproteinase- 9 gene is not associated with cognitive performance in healthy participants. Psychiatr Genet 19:277-278.

Rylski M, Amborska R, Zybura K, Michaluk P, Bielinska B, Konopacki FA, Wilczynski GM, Kaczmarek L (2009) JunB is a repressor of MMP-9 transcription in depolarized rat brain neurons. Mol Cell Neurosci 40:98-110.

Sagane K, Yamazaki K, Mizui Y, Tanaka I (1999) Cloning and chromosomal mapping of mouse ADAM11, ADAM22 and ADAM23. Gene 236:79-86.

Sagane K, Hayakawa K, Kai J, Hirohashi T, Takahashi E, Miyamoto N, Ino M, Oki T, Yamazaki K, Nagasu T (2005) Ataxia and peripheral nerve hypomyelination in ADAM22-deficient mice. BMC Neurosci 6:33.

Samochowiec A, Grzywacz A, Kaczmarek L, Bienkowski P, Samochowiec J, Mierzejewski P, Preuss UW, Grochans E, Ciechanowicz A (2010) Functional polymorphism of matrix metalloproteinase-9 (MMP-9) gene in alcohol dependence: family and case control study. Brain Res 1327:103-136.

Sandy JD, Neame PJ, Boynton RE, Flannery CR (1991) Catabolism of ag- grecan in cartilage explants. Identification of a major cleavage site within the interglobular domain. J Biol Chem 266:8683-8685.

Sandy JD, Westling J, Kenagy RD, Iruela-Arispe ML, Verscharen C, Rodriguez-Mazaneque JC, Zimmermann DR, Lemire JM, Fischer JW, Wight TN, Clowes AW (2001) Versican V1 proteolysis in human aorta in vivo occurs at the $\mathrm{Glu}^{441}-\mathrm{Ala}^{442}$ bond, a site that is cleaved by recombinant ADAMTS-1 and ADAMTS-4. J Biol Chem 276:13372-13378.

Sbai O, Ferhat L, Bernard A, Gueye Y, Ould-Yahoui A, Thiolloy S, Charrat E, Charton G, Tremblay E, Risso JJ, Chauvin JP, Arsanto JP, Rivera S, Khrestchatisky M (2008) Vesicular trafficking and secretion of matrix metalloproteinases-2, -9 and tissue inhibitor of metalloproteinases- 1 in neuronal cells. Mol Cell Neurosci 39:549-568.

Sbai O, Ould-Yahoui A, Ferhat L, Gueye Y, Bernard A, Charrat E, Mehanna A, Risso JJ, Chauvin JP, Fenouillet E, Rivera S, Khrestchatisky M (2010) Differential vesicular distribution and trafficking of MMP-2, MMP-9, and their inhibitors in astrocytes. Glia 58:344-366.

Schiffer D, Cavalla P, Dutto A, Borsotti L (1997) Cell proliferation and invasion in malignant gliomas. Anticancer Res 17:61-69.

Schimmelpfeng K, Gögel S, Klämbt C (2001) The function of leak and kuzbanian during growth cone and cell migration. Mech Dev 106:25-36.

Schmitt U, Hiemke C, Fahrenholz F, Schroeder A (2006) Over-expression of two different forms of the $\alpha$-secretase ADAM10 affects learning and memory in mice. Behav Brain Res 175:278-284.

Schönbeck U, Mach F, Libby P (1998) Generation of biologically active IL- $1 \beta$ by matrix metalloproteinases: a novel caspase-1-independent pathway of IL-1 $\beta$ processing. J Immunol 161:3340-3346.

Schulz R (2007) Intracellular targets of matrix metalloproteinase-2 in cardiac disease: rationale and therapeutic approaches. Annu Rev Pharmacol Toxicol 47:211-242.

Schwab ME, Caroni P (1988) Oligodendrocytes and CNS myelin are nonpermissive substrates for neurite growth and fibroblast spreading in vitro. J Neurosci 8:2381-2393.

Sela-Passwell N, Rosenblum G, Shoham T, Sagi I (2010) Structural and functional bases for allosteric control of MMP activities: can it pave the path for selective inhibition? Biochim Biophys Acta 1803:29-38.

Seo DW, Li H, Guedez L, Wingfield PT, Diaz T, Salloum R, Wei BY, StetlerStevenson WG (2003) TIMP-2 mediated inhibition of angiogenesis: an MMP-independent mechanism. Cell 114:171-180.

Shiryaev SA, Remacle AG, Savinov AY, Chernov AV, Cieplak P, Radichev IA, Williams R, Shiryaeva TN, Gawlik K, Postnova TI, Ratnikov BI, Eroshkin AM, Motamedchaboki K, Smith JW, Strongin AY (2009) Inflammatory proprotein convertase-matrix metalloproteinase proteolytic pathway in antigen-presenting cells as a step to autoimmune multiple sclerosis. J Biol Chem 284:30615-30626.

Sillanaukee P, Kalela A, Seppä K, Höyhtyä M, Nikkari ST (2002) Matrix metalloproteinase- 9 is elevated in serum of alcohol abusers. Eur J Clin Invest 32:225-229.

Singh SK, Hawkins C, Clarke ID, Squire JA, Bayani J, Hide T, Henkelman RM, Cusimano MD, Dirks PB (2004) Identification of human brain tumour initiating cells. Nature 432:396-401.

Skoog I, Wallin A, Fredman P, Hesse C, Aevarsson O, Karlsson I, Gottfries CG, Blennow K (1998) A population study on blood-brain barrier function in 85-year-olds: relation to Alzheimer's disease and vascular dementia. Neurology 50:966-971.

Snowdon DA, Greiner LH, Mortimer JA, Riley KP, Greiner PA, Markesbery WR (1997) Brain infarction and the clinical expression of Alzheimer disease. The Nun Study. JAMA 277:813-817.

Sood R, Yang Y, Taheri S, Candelario-Jalil E, Estrada EY, Walker EJ, Thompson J, Rosenberg GA (2009) Increased apparent diffusion coefficients on MRI linked with matrix metalloproteinases and edema in white matter after bilateral carotid artery occlusion in rats. J Cereb Blood Flow Metab 29:308-316.

Sounni NE, Rozanov DV, Remacle AG, Golubkov VS, Noel A, Strongin AY (2010) TIMP-2 binding with cellular MT1-MMP stimulates invasionpromoting MEK/ERK signaling in cancer cells. Int J Cancer 126:1067-1078.

Stetler-Stevenson WG (2008a) The tumor microenvironment: regulation by MMP-independent effects of tissue inhibitor of metalloproteinases-2. Cancer Metastasis Rev 27:57-66.

Stetler-Stevenson WG (2008b) Tissue inhibitors of metalloproteinases in cell signaling: metalloproteinase-independent biological activities. Sci Signal:re6.

Stiles CD, Rowitch DH (2008) Glioma stem cells: a midterm exam. Neuron $58: 832-846$. 
Strongin AY (2010) Proteolytic and non-proteolytic roles of membrane type-1 matrix metalloproteinase in malignancy. Biochim Biophys Acta 1803:133-141.

Suzuki M, Raab G, Moses MA, Fernandez CA, Klagsbrun M (1997) Matrix metalloproteinase-3 releases active heparin-binding EGF-like growth factor by cleavage at a specific juxtamembrane site. J Biol Chem 272:31730-31737.

Szklarczyk A, Lapinska J, Rylski M, McKay RD, Kaczmarek L (2002) Matrix metalloproteinase-9 undergoes expression and activation during dendritic remodeling in adult hippocampus. J Neurosci 22:920-930.

Takács E, Nyilas R, Szepesi Z, Baracskay P, Karlsen B, Røsvold T, Bjørkum AA, Czurkó A, Kovács Z, Kékesi AK, Juhász G (2010) Matrix metalloproteinase- 9 activity increased by two different types of epileptic seizures that do not induce neuronal death: a possible role in homeostatic synaptic plasticity. Neurochem Int 56:799-809.

Takahashi C, Sheng Z, Horan TP, Kitayama H, Maki M, Hitomi K, Kitaura Y, Takai S, Sasahara RM, Horimoto A, Ikawa Y, Ratzkin BJ, Arakawa T, Noda M (1998) Regulation of matrix metalloproteinase-9 and inhibition of tumor invasion by the membrane-anchored glycoprotein RECK. Proc Natl Acad Sci U S A 95:13221-13226.

Taniwaki K, Fukamachi H, Komori K, Ohtake Y, Nonaka T, Sakamoto T, Shiomi T, Okada Y, Itoh T, Itohara S, Seiki M, Yana I (2007) Stromaderived matrix metalloproteinase (MMP)-2 promotes membrane type 1-MMP-dependent tumor growth in mice. Cancer Res 67:4311-4319.

Tian L, Stefanidakis M, Ning L, Van Lint P, Nyman-Huttunen H, Libert C, Itohara S, Mishina M, Rauvala H, Gahmberg CG (2007a) Activation of NMDA receptors promotes dendritic spine development through MMPmediated ICAM-5 cleavage. J Cell Biol 178:687-700.

Tian YF, Zhang PB, Xiao XL, Zhang JS, Zhao JJ, Kang QY, Chen XL, Qiu F, Liu $Y$ (2007b) The quantification of ADAMTS expression in an animal model of cerebral ischemia using real-time PCR. Acta Anaesthesiol Scand 51:158-164.

Tomimoto H, Ihara M, Wakita H, Ohtani R, Lin JX, Akiguchi I, Kinoshita M, Shibasaki H (2003) Chronic cerebral hypoperfusion induces white matter lesions and loss of oligodendroglia with DNA fragmentation in the rat. Acta Neuropathol (Berl) 106:527-534.

Tsuji K, Aoki T, Tejima E, Arai K, Lee SR, Atochin DN, Huang PL, Wang X, Montaner J, Lo EH (2005) Tissue plasminogen activator promotes matrix metalloproteinase- 9 upregulation after focal cerebral ischemia. Stroke 36:1954-1959.

Ugalde AP, Ordóñez GR, Quirós PM, Puente XS, López-Otín C (2010) Metalloproteases and the degradome. Methods Mol Biol 622:3-29.

Ulrich R, Gerhauser I, Seeliger F, Baumgärtner W, Alldinger S (2005) Matrix metalloproteinases and their inhibitors in the developing mouse brain and spinal cord: a reverse transcription quantitative polymerase chain reaction study. Dev Neurosci 27:408-418.

Vaillant C, Didier-Bazès M, Hutter A, Belin MF, Thomasset N (1999) Spatiotemporal expression patterns of metalloproteinases and their inhibitors in the postnatal developing rat cerebellum. J Neurosci 19:4994-5004.

Vaillant C, Meissirel C, Mutin M, Belin MF, Lund LR, Thomasset N (2003) MMP-9 deficiency affects axonal outgrowth, migration, and apoptosis in the developing cerebellum. Mol Cell Neurosci 24:395-408.

van der Vlies AE, Verwey NA, Bouwman FH, Blankenstein MA, Klein M, Scheltens P, van der Flier WM (2009) CSF biomarkers in relationship to cognitive profiles in Alzheimer disease. Neurology 72:1056-1061.

Van Meir EG, Hadjipanayis CG, Norden AD, Shu HK, Wen PY, Olson JJ (2010) Exciting new advances in neuro-oncology: the avenue to a cure for malignant glioma. CA Cancer J Clin 60:166-193.

Vassos E, Ma X, Fiotti N, Wang Q, Sham PC, Liu X, Wang Y, Yan C, Meng H, Deng W, Collier DA, Li T (2008) The functional MMP-9 microsatellite marker is not associated with episodic memory in humans. Psychiatr Genet 18:252.

Velasco G, Cal S, Merlos-Suárez A, Ferrando AA, Alvarez S, Nakano A, Arribas J, López-Otín C (2000) Human MT6-matrix metalloproteinase: identification, progelatinase A activation, and expression in brain tumors. Cancer Res 60:877-882.

Verhaak RG, Hoadley KA, Purdom E, Wang V, Qi Y, Wilkerson MD, Miller CR, Ding L, Golub T, Mesirov JP, Alexe G, Lawrence M, O'Kelly M, Tamayo P, Weir BA, Gabriel S, Winckler W, Gupta S, Jakkula L, Feiler HS, et al. (2010) Integrated genomic analysis identifies clinically relevant subtypes of glioblastoma characterized by abnormalities in PDGFRA, IDH1, EGFR, and NF1. Cancer Cell 17:98-110.
Viapiano MS, Bi WL, Piepmeier J, Hockfield S, Matthews RT (2005) Novel tumor-specific isoforms of BEHAB/brevican identified in human malignant gliomas. Cancer Res 65:6726-6733.

Viapiano MS, Hockfield S, Matthews RT (2008) BEHAB/brevican requires ADAMTS-mediated proteolytic cleavage to promote glioma invasion. J Neurooncol 88:261-272.

Walker EJ, Rosenberg GA (2009) TIMP-3 and MMP-3 contribute to delayed inflammation and hippocampal neuronal death following global ischemia. Exp Neurol 216:122-131.

Wallin AK, Blennow K, Zetterberg H, Londos E, Minthon L, Hansson O (2010) CSF biomarkers predict a more malignant outcome in Alzheimer disease. Neurology 74:1531-1537.

Wallin A, Sjögren M, Edman A, Blennow K, Regland B (2000) Symptoms, vascular risk factors and blood-brain barrier function in relation to CT white-matter changes in dementia. Eur Neurol 44:229-235.

Wang L, Zhang ZG, Zhang RL, Gregg SR, Hozeska-Solgot A, LeTourneau Y, Wang Y, Chopp M (2006) Matrix metalloproteinase 2 (MMP2) and MMP9 secreted by erythropoietin-activated endothelial cells promote neural progenitor cell migration. J Neurosci 26:5996-6003.

Wang XB, Bozdagi O, Nikitczuk JS, Zhai ZW, Zhou Q, Huntley GW (2008) Extracellular proteolysis by matrix metalloproteinase- 9 drives dendritic spine enlargement and long-term potentiation coordinately. Proc Natl Acad Sci U S A 105:19520-19525.

Wang Z, Juttermann R, Soloway PD (2000) TIMP-2 is required for efficient activation of proMMP-2 in vivo. J Biol Chem 275:26411-26415.

Wardlaw JM, Doubal F, Armitage P, Chappell F, Carpenter T, Muñoz Maniega S, Farrall A, Sudlow C, Dennis M, Dhillon B (2009) Lacunar stroke is associated with diffuse blood-brain barrier dysfunction. Ann Neurol 65:194-202.

Webber CA, Hocking JC, Yong VW, Stange CL, McFarlane S (2002) Metalloproteases and guidance of retinal axons in the developing visual system. J Neurosci 22:8091-8100.

Wells JE, Rice TK, Nuttall RK, Edwards DR, Zekki H, Rivest S, Yong VW (2003) An adverse role for matrix metalloproteinase 12 after spinal cord injury in mice. J Neurosci 23:10107-10115.

Wen PY, Kesari S (2008) Malignant gliomas in adults. N Engl J Med 359:492-507.

Wetzel M, Rosenberg GA, Cunningham LA (2003) Tissue inhibitor of metalloproteinases- 3 and matrix metalloproteinase- 3 regulate neuronal sensitivity to doxorubicin-induced apoptosis. Eur J Neurosci 18:1050-1060

Wetzel M, Li L, Harms KM, Roitbak T, Ventura PB, Rosenberg GA, Khokha $\mathrm{R}$, Cunningham LA (2008) Tissue inhibitor of metalloproteinases- $3 \mathrm{fa}-$ cilitates Fas-mediated neuronal cell death following mild ischemia. Cell Death Differ 15:143-151.

Wiediger RV, Wright JW (2009) Influence of dorsal hippocampal lesions and MMP inhibitors on spontaneous recovery following a habituation/ classical conditioning head-shake task. Neurobiol Learn Mem 92:504-511.

Wilczynski GM, Konopacki FA, Wilczek E, Lasiecka Z, Gorlewicz A, Michaluk P, Wawrzyniak M, Malinowska M, Okulski P, Kolodziej LR, Konopka W, Duniec K, Mioduszewska B, Nikolaev E, Walczak A, Owczarek D, Gorecki DC, Zuschratter W, Ottersen OP, Kaczmarek L (2008) Important role of matrix metalloproteinase 9 in epileptogenesis. J Cell Biol 180:1021-1035.

Wildeboer D, Naus S, Amy Sang QX, Bartsch JW, Pagenstecher A (2006) Metalloproteinase disintegrins ADAM8 and ADAM19 are highly regulated in human primary brain tumors and their expression levels and activities are associated with invasiveness. J Neuropathol Exp Neurol 65:516-527.

Wójtowicz T, Mozrzymas JW (2010) Late phase of long term potentiation in the mossy fiber-CA3 hippocampal pathway is critically dependent on metalloproteinases activity. Hippocampus 20:917-921.

Wright JW, Harding JW (2009) Contributions of matrix metalloproteinases to neural plasticity, habituation, associative learning and drug addiction. Neural Plast 2009:579382.

Wright JW, Masino AJ, Reichert JR, Turner GD, Meighan SE, Meighan PC, Harding JW (2003) Ethanol-induced impairment of spatial memory and brain matrix metalloproteinases. Brain Res 963:252-261.

Wright JW, Meighan SE, Murphy ES, Holtfreter KL, Davis CJ, Olson ML, Benoist CC, Muhunthan K, Harding JW (2006) Habituation of the head-shake re- 
sponse induces changes in brain matrix metalloproteinases-3 (MMP-3) and -9. Behav Brain Res 174:78-85.

Wright JW, Brown TE, Harding JW (2007) Inhibition of hippocampal matrix metalloproteinase- 3 and -9 disrupts spatial memory. Neural Plast 2007:73813.

Wright JW, Meighan PC, Brown TE, Wiediger RV, Sorg BA, Harding JW (2009) Habituation-induced neural plasticity in the hippocampus and prefrontal cortex mediated by MMP-3. Behav Brain Res 203:27-34.

Yamada H, Fredette B, Shitara K, Hagihara K, Miura R, Ranscht B, Stallcup WB, Yamaguchi Y (1997) The brain chondroitin sulfate proteoglycan brevican associates with astrocytes ensheathing cerebellar glomeruli and inhibits neurite outgrowth from granule neurons. J Neurosci 17:7784-7795.

Yang P, Baker KA, Hagg T (2005) A disintegrin and metalloprotease 21 (ADAM21) is associated with neurogenesis and axonal growth in developing and adult rodent CNS. J Comp Neurol 490:163-179.

Yang P, Baker KA, Hagg T (2006) The ADAMs family: coordinators of nervous system development, plasticity and repair. Prog Neurobiol 79:73-94.

Yang Y, Estrada EY, Thompson JF, Liu W, Rosenberg GA (2007) Matrix metalloproteinase-mediated disruption of tight junction proteins in cerebral vessels is reversed by synthetic matrix metalloproteinase inhibitor in focal ischemia in rat. J Cereb Blood Flow Metab 27:697-709.

Yang Y, Candelario-Jalil E, Thompson JF, Cuadrado E, Estrada EY, Rosell A, Montaner J, Rosenberg GA (2010) Increased intranuclear matrix metalloproteinase activity in neurons interferes with oxidative DNA repair in focal cerebral ischemia. J Neurochem 112:134-149.

Yin KJ, Cirrito JR, Yan P, Hu X, Xiao Q, Pan X, Bateman R, Song H, Hsu FF, Turk J, Xu J, Hsu CY, Mills JC, Holtzman DM, Lee JM (2006) Matrix metalloproteinases expressed by astrocytes mediate extracellular amyloid-beta peptide catabolism. J Neurosci 26:10939-10948.

Yiotakis A, Dive V (2008) Synthetic active site-directed inhibitors of metzincing: achievement and perspectives. Mol Aspects Med 29:329-338.

Yong VW (2005) Metalloproteinases: mediators of pathology and regeneration in the CNS. Nat Rev Neurosci 6:931-944.
Yong VW, Zabad RK, Agrawal S, Goncalves Dasilva A, Metz LM (2007) Elevation of matrix metalloproteinases (MMPs) in multiple sclerosis and impact of immunomodulators. J Neurol Sci 259:79-84.

Yuan W, Matthews RT, Sandy JD, Gottschall PE (2002) Association between protease-specific proteolytic cleavage of brevican and synaptic loss in the dentate gyrus of kainate-treated rats. Neuroscience 114:1091-1101.

Zagulska-Szymczak S, Filipkowski RK, Kaczmarek L (2001) Kainateinduced genes in the hippocampus: lessons from expression patterns. Neurochem Int 38:485-501.

Zhang C, An J, Haile WB, Echeverry R, Strickland DK, Yepes M (2009) Microglial low-density lipoprotein receptor-related protein 1 mediates the effect of tissue-type plasminogen activator on matrix metalloproteinase-9 activity in the ischemic brain. J Cereb Blood Flow Metab 29:1946-1954.

Zhang H, Kelly G, Zerillo C, Jaworski DM, Hockfield S (1998) Expression of a cleaved brain-specific extracellular matrix protein mediates glioma cell invasion in vivo. J Neurosci 18:2370-2376.

Zhang Y, Klassen HJ, Tucker BA, Perez MT, Young MJ (2007) CNS progenitor cells promote a permissive environment for neurite outgrowth via a matrix metalloproteinase-2-dependent mechanism. J Neurosci 27:4499-4506.

Zhao J, Chen H, Peschon JJ, Shi W, Zhang Y, Frank SJ, Warburton D (2001) Pulmonary hypoplasia in mice lacking tumor necrosis factor-alpha converting enzyme indicates an indispensable role for cell surface protein shedding during embryonic lung branching morphogenesis. Dev Biol 232:204-218.

Zheng X, Jiang F, Katakowski M, Kalkanis SN, Hong X, Zhang X, Zhang ZG, Yang H, Chopp M (2007) Inhibition of ADAM17 reduces hypoxiainduced brain tumor cell invasiveness. Cancer Sci 98:674-684.

Zhou Z, Nguyen TC, Guchhait P, Dong JF (2010) Von Willebrand factor, ADAMTS-13, and thrombotic thrombocytopenic purpura. Semin Thromb Hemost 36:71-81.

Zuo J, Ferguson TA, Hernandez YJ, Stetler-Stevenson WG, Muir D (1998) Neuronal matrix metalloproteinase-2 degrades and inactivates a neuriteinhibiting chondroitin sulfate proteoglycan. J Neurosci 18:5203-5211. 